\title{
Doping of high-Al-content AlGaN grown by MOCVD
}

\author{
Daniel Nilsson
}

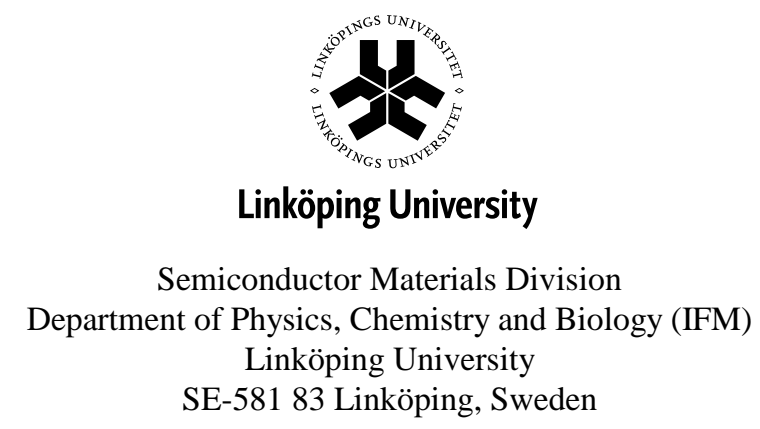

Linköping 2014 
(c) Daniel Nilsson

ISSN 0345-7524

ISBN 978-91-7519-332-8

Printed in Sweden by LIU-tryck 2014 


\section{Abstract}

The high-Al-content $\mathrm{Al}_{\mathrm{x}} \mathrm{Ga}_{1-\mathrm{x}} \mathrm{N}, \mathrm{x}>0.70$, is the principal wide-band-gap alloy system to enable the development of light-emitting diodes operating at the short wavelengths in the deep-ultraviolet, $\lambda<$ $280 \mathrm{~nm}$. The development of the deep-ultraviolet light-emitting diodes (DUV LEDs) is driven by the social and market impact expected from their implementation in portable units for water/surface disinfection and based on the damaging effect of the deep-ultraviolet radiation on the DNA of various microorganisms. Internationally, intense research and technology developments occur in the past few years, yet, the external quantum efficiency of the DUV LEDs is typically below $1 \%$.

One of the main material issues in the development of the DUV LEDs is the achievement of $n$ - and $p$ type high-Al-content $\mathrm{Al}_{\mathrm{x}} \mathrm{Ga}_{1-\mathrm{x}} \mathrm{N}$ layers with low resistivity, which is required for the electrical pumping of the diodes. The doping process becomes significantly more complex with increasing the $\mathrm{Al}$ content and the electrical resistivity is as high as $10^{1}-10^{2} \Omega \mathrm{cm}$ for n-type AlN doped by silicon, and $10^{7}-10^{8} \Omega \mathrm{cm}$ for p-type AlN doped by magnesium.

The present study was therefore focused on gaining a better understanding of the constraints in the doping process of the high-Al-content $\mathrm{Al}_{x} \mathrm{Ga}_{1-\mathrm{x}} \mathrm{N}$ alloys, involving mainly silicon. For this purpose, the epitaxial growth of the high-Al-content $\mathrm{Al}_{\mathrm{x}} \mathrm{Ga}_{1-\mathrm{x}} \mathrm{N}$ and $\mathrm{AlN}$ by implementing the distinct hot-wall MOCVD was developed in order to achieve layers of good structural and morphological properties, and with low content of residual impurities, particularly oxygen and carbon. Substitutional point defects $\mathrm{O}_{\mathrm{N}}$ and $\mathrm{C}_{\mathrm{N}}$ may have a profound impact on the doping by their involvement in effects of $n$ type carrier compensation. The process temperature was varied between 1000 and up to $1400{ }^{\circ} \mathrm{C}$, which is a principal advantage in order to optimize the material properties of the high-Al-content $\mathrm{Al}_{\mathrm{x}} \mathrm{Ga}_{1-\mathrm{x}} \mathrm{N}$ and AlN. The epitaxial growth of the high-Al-content $\mathrm{Al}_{\mathrm{x}} \mathrm{Ga}_{1-\mathrm{x}} \mathrm{N}$ and $\mathrm{AlN}$ was largely performed on $4 \mathrm{H}-\mathrm{SiC}$ substrates motivated by (i) the lattice mismatch of $\sim 1 \%$ along the basal plane (the smallest among other available substrates including $\mathrm{Si}$ and sapphire), (ii) the good thermal conductivity of $3.7 \mathrm{~W} \mathrm{~cm}^{-1} \mathrm{~K}^{-1}$, which is essential to minimize the self-heating during the operation of any light-emitting diode, and (iii) the limited access to true-bulk AlN wafers. The Si doping was investigated over a large range of $[\mathrm{Si}] \sim 1 \times 10^{17} \mathrm{~cm}^{-3}-1 \times 10^{20} \mathrm{~cm}^{-3}$. Only the high doping range of $[\mathrm{Mg}] \sim(1-3) \times 10^{19} \mathrm{~cm}^{-3}$ was targeted motivated by the large thermal ionization energy of this common acceptor (from $200 \mathrm{meV}$ in $\mathrm{GaN}$ to about $630 \mathrm{meV}$ in $\mathrm{AlN}$ ). The material characterization involved extensive implementation of atomic force microscopy (AFM), x-ray diffraction (XRD), cathodoluminescence (CL), secondary ion mass spectrometry (SIMS), capacitance-voltage measurements, as well as measurements of the conductivity of the layers by contactless microwavebased technique. The possibility to perform electron paramagnetic resonance (EPR) measurements on the Si-doped high-Al-content $\mathrm{Al}_{\mathrm{x}} \mathrm{Ga}_{1-\mathrm{x}} \mathrm{N}$ was essential in order to establish any effect of selfcompensation of the shallow donor state of silicon through the related so-called DX state. The EPR measurements corroborated the study of the incorporation kinetics of silicon and oxygen at various process temperatures and growth rates.

The outcome of this study is accordingly summarized and presents our understanding for (i) the complex impact of silicon and oxygen on the $n$-type conductivity of $\mathrm{Al}_{0.77} \mathrm{Ga}_{0.23} \mathrm{~N}$, representative for the alloy composition at which a drastic reduction of the $n$-type conductivity of $\mathrm{Al}_{\mathrm{x}} \mathrm{Ga}_{1-\mathrm{x}} \mathrm{N}$ is commonly reported (paper 1); (ii) the strain and morphology compliance during the intentional 
doping by silicon and magnesium, and its correlation with the resistivity of highly doped layers of $\mathrm{Al}_{0.82} \mathrm{Ga}_{0.18} \mathrm{~N}$ alloy composition (paper2); (iii) the $n$-type conductivity of highly Si-doped $\mathrm{Al}_{0.72} \mathrm{Ga}_{0.28} \mathrm{~N}$ as bound by the process temperature (paper 3); and (iv) the shallow donor or DX behavior of silicon in conductive $\mathrm{Al}_{\mathrm{x}} \mathrm{Ga}_{1-\mathrm{x}} \mathrm{N}$ layers with $0.63 \leq \mathrm{x} \leq 1$ (paper 4). It is noted that the measured $n$-type conductivity in reference layers of $\mathrm{Al}_{0.77} \mathrm{Ga}_{0.23} \mathrm{~N}$, alternatively $\mathrm{Al}_{0.72} \mathrm{Ga}_{0.28} \mathrm{~N}$, alloy composition is on par with the state-of-the-art values, i.e. $\leq 0.05 \Omega \mathrm{cm}$, and $0.012 \Omega \mathrm{cm}$, respectively. A room-temperature resistivity of $7 \mathrm{k} \Omega \mathrm{cm}$ was measured in Mg-doped layers of $\mathrm{Al}_{0.85} \mathrm{Ga}_{0.15} \mathrm{~N}$ alloy composition, which is superior to the state-of-art values (paper 5). The performance of the transport properties of the high-Al-content $\mathrm{Al}_{\mathrm{x}} \mathrm{Ga}_{1-\mathrm{x}} \mathrm{N}$ layers can further improve by improving the crystalline quality of the AlN-on-SiC template and by implementing true-bulk AlN substrates. The AlN heteroepitaxial growth at the process temperatures of 1100 and $1200{ }^{\circ} \mathrm{C}$ is therefore investigated (paper 6). The lattice parameters, structural and optical properties of true-bulk, homoepitaxial and heteroepitaxial AlN material grown at high process temperatures of up to $1400{ }^{\circ} \mathrm{C}$ is further reported (paper 7). 


\section{Populärvetenskaplig sammanfattning}

Aluminium-gallium-nitrid $\left(\mathrm{Al}_{\mathrm{x}} \mathrm{Ga}_{1-\mathrm{x}} \mathrm{N}\right)$ med hög Aluminium halt $(\mathrm{x}>0.7)$ är en legering som tillhör materialklassen halvledare och har ett enormt brett och direkt band-gap upp till $6.2 \mathrm{eV}$ för AlN. Denna egenskap gör denna legering optimal för att tillverka mycket små och effektiva optoelektroniska komponenter, så som till exempel lysdioder och laserdioder, som kan emitterar ultraviolett (UV) ljus med en våglängder kortare än $280 \mathrm{~nm}$. UV ljus med denna våglängd skadar cellers DNA molekyler och kan därför användas för desinfektion av förorenat vatten och luft. Denna viktiga tillämpning har starkt drivit utvecklingen av detta material system framåt, men än så länge är effektiviteten hos dessa komponenter mycket lägre än för till exempel lysdioder som emitterar blått eller rött ljus.

För att utnyttja dessa unika materialetegenskaper för optoelektroniska tillämpningar är det nödvändigt att erhålla en mycket hög kristallkvalitet och att kunna kontrollera dess elektriska ledningsförmåga genom att tillsätta små koncentrationer av föroreningar eller så kallat störämne. Denna process kallas dopning. Störämnen som avger en extra elektron till materialet kallas donatorer (bidrar till n-typ konduktivitet) medan störämnen som binder en extra elektron och bildar elektriskt ledande "hål" kallas acceptorer (p-typ konduktivitet). När elektroner och hål möts kan energi frigöras genom att bland annat emittera UV ljus. Vanligen används störämena $\mathrm{Si}$ (donator) och $\mathrm{Mg}$ (acceptor) för att kontrollera konduktiviteten hos $\mathrm{GaN}$ och $\mathrm{AlGaN}$. Men vid höga Aluminium halter är det svårt att kontrollera den elektroniska ledningsförmågan till den grad som krävs för att tillverka effektiva ultravioletta lysdioder. Därför är det viktigt att utforska och förstå de grundläggande egenskaperna hos störatomer samt hur de påverkar tillväxt processen av AlGaN.

I denna avhandling har dopning processen av AlGaN med hög Aluminium halt studerats ( $\mathrm{x}>$ 0.6). Den tillväxt process som har används i detta arbete är, metalorganic chemical vapor deposition (MOCVD), som idag är den dominerande tillväxt metoden för optoelektroniska komponent-strukturer. För att odla $\mathrm{AlGaN}$ med MOCVD används vanligtvis de metalorganiskaföreningarna Trimetylaluminium $\left(\mathrm{Al}\left(\mathrm{CH}_{3}\right)_{3}\right)$ och Trimetylgallium $\left(\mathrm{Ga}\left(\mathrm{CH}_{3}\right)_{3}\right)$ samt gasen ammoniak $\left(\mathrm{NH}_{3}\right)$. Dessa föreningar flödar sedan tillsammans med stora mängder vätgas över ett kiselkarbid- ( $\mathrm{SiC}$ ) eller AlN-substrat som har värmts upp till en temperatur av $\sim 1000-1500{ }^{\circ} \mathrm{C}$ under ett lågt processtryck av 50 mbar. De kemiskaföreningarna reagerar över det varma substratet och formar $\mathrm{AlGaN}$. Under detta projekt studerades initialt tillväxten av AlN, för att erhålla den höga kristallkvalité och de låga bakgrunds nivåer av föroreningar så som syre och kol, som krävs för att kunna erhålla kontrollerad dopning. Detta kan uppnås bland annat genom att använda relativt höga tillväxt temperaturer och låga tillväxthastigheter. Dopning och dess inverkan på den elektriska ledningsförmågan och materialkvaliteten studerades sedan i detalj genom att växa dopad AlGaN på dessa högkvalitativa AlN filmer. Genom att tillsätta små flöden av Si och Mg innehållande föreningar till MOCVD processen kan materialet dopas med önskade koncentrationer med $\mathrm{Si}$ eller $\mathrm{Mg}$. Hur dessa atomer inkorporerar $\mathrm{i}$ kristallen och hur den elektriska konduktiviteten påverkakas av tillväxtparameterar så som tillväxthastighet, dopning koncentration och processtemperatur har undersökts. Arbetet har resulterat i kontrollerad konduktivitet vid Aluminium halter upp till 80-85 \% för både n-typ och p-typ dopad AlGaN vilket möjliggör tillverkning av UV emitterande optoelektroniska komponenter med extremt korta våglängder, $\lambda \sim 230-240 \mathrm{~nm}$. Vi har också presenterat en möjlig förklaring för den låga n-typ konduktiviteten observerad hos 
AlN, där vi föreslår att Si bildar en stabil djup donatornivå (DX-center) som kräver en relativt hög termiskenergi för att frigöra de donator bundna elektronerna. 


\section{Preface}

This thesis is based on my PhD studies conducted from May 2009 to May 2014 in the Division of Semiconductor Materials, Department of Physics, Chemistry and Biology (IFM), Linköping University. Financial support was provided by the Swedish Research Council (VR) and Swedish Foundation for Strategic Research (SSF). 


\section{Papers included in the thesis}

1. The complex impact of silicon and oxygen on the n-type conductivity of high-Alcontent AlGaN

A. Kakanakova-Georgieva, D. Nilsson, X. T. Trinh, U. Forsberg, N. T. Son, and E. Janzén

Applied Physics Letters 102 (2013) 132113

2. Strain and morphology compliance during the intentional doping of high-Alcontent AlGaN layers

D. Nilsson, E. Janzén, and A. Kakanakova-Georgieva

submitted

3. Highly Si-doped $\mathrm{Al}_{0.72} \mathrm{Ga}_{0.28} \mathrm{~N}$ layers: $\mathrm{n}$-type conductivity bound by the process temperature

D. Nilsson, X. T. Trinh, N. T. Son, E. Janzén, S.-L. Lata, M. J. Kappers, C. J. Humphreys, and A. Kakanakova-Georgieva

Manuscript

4. On the behavior of the silicon donor in conductive $\mathrm{Al}_{\mathrm{x}} \mathrm{Ga}_{1-\mathrm{x}} \mathrm{N}(0.63 \leq \mathrm{x} \leq 1)$ layers

D. Nilsson, X. T. Trinh, E. Janzén, N. T. Son, and A. Kakanakova-Georgieva

Manuscript in final preparation

5. Mg-doped $\mathrm{Al}_{0.85} \mathrm{Ga}_{0.15} \mathrm{~N}$ layers grown by hot-wall MOCVD with low resistivity at room temperature

A. Kakanakova-Georgieva, D. Nilsson, M. Stattin, U. Forsberg, A. Haglund, A. Larsson, and E. Janzén

Physica Status Solidi - Rapid Research Letters 4 (2010) 311

6. High-quality AIN layers grown by hot-wall MOCVD at reduced temperatures

A. Kakanakova-Georgieva, D. Nilsson, and E. Janzén

Journal of Crystal Growth 338 (2012) 52

7. Lattice parameters, structural and optical properties of AlN true bulk, homoepitaxial and heteroepitaxial material grown at high temperatures of up to $1400{ }^{\circ} \mathrm{C}$

D. Nilsson, E. Janzén, and A. Kakanakova-Georgieva

Manuscript 


\section{My contribution to the papers}

Paper 1.I performed the growth, AFM and electrical characterization, and took part in the CLSEM measurements. I participated in the analysis and discussions of the data, and in the writing of the paper.

Paper 2.I planned and performed the growth, AFM and XRD characterization. I participated in the analysis and discussions of the data, and in the writing of the manuscript.

Paper 3. I planned and performed the growth, AFM, XRD, and electrical characterization. I participated in the analysis and discussions of the data, and in the writing of the manuscript.

Paper 4. I planned and performed the growth, AFM, XRD, and electrical characterization. I wrote the manuscript after discussions and inputs from the co-authors.

Paper 5. I performed the AFM characterization and took part in the growth. I participated in the analysis and discussions of the data, and in the writing of the paper.

Paper 6. I performed the AFM characterization and took part in the CL-SEM measurements. I participated in the discussions of the data, and in the writing of the paper.

Paper 7. I planned and performed a major part of the growth. I performed the XRD and CLSEM characterization. I wrote the manuscript draft. 


\section{Papers related to the thesis}

8. Silicon and oxygen in high-Al-content AIGaN: incorporation kinetics and electron paramagnetic resonance study

A. Kakanakova-Georgieva, D. Nilsson, X.T. Trinh, N.T. Son, and E. Janzén

Diffusion and Defect Data Pt.B: Solid State Phenomena 205-206 (2014) 441

9. Direct generation of linearly-polarized photon emission with designated orientations from site-controlled InGaN quantum dots

A. Lundskog, C-W. Hsu, F. K. Karlsson, S. Amloy, D. Nilsson, U. Forsberg, P. O. Holtz, and E. Janzén

Light: science \& applications 3 (2014) 140

10. Electron effective mass in $\mathrm{Al}_{0.72} \mathrm{Ga}_{0.28} \mathrm{~N}$ alloys determined by mid-infrared optical hall effect

S. Schöche, P. Kühne, T. Hofmann, M. Schubert, D. Nilsson, A. KakanakovaGeorgieva, E. Janzén, and V. Darakchieva

Applied Physics Letters 103 (2013) 212107

11. Negative-U behavior of the $\mathrm{Si}$ donor in $\mathrm{Al}_{0.77} \mathrm{Ga}_{0.23} \mathrm{~N}$

X. T. Trinh, D. Nilsson, I. G. Ivanov, E. Janzén, A. Kakanakova-Georgieva, and N. T. Son

Applied Physics Letters 103 (2013) 042101

12. Controlled growth of hexagonal GaN pyramids by hot-wall MOCVD

A. Lundskog, C.W. Hsu, D. Nilsson, K.F. Karlsson, U. Forsberg, P.O. Holtz, and E. Janzén

Journal of Crystal Growth 363 (2013) 287 


\section{Acknowledgement}

This thesis would not be possible if it was not for all colleagues and friends that have supported, inspired and helped me during this work. The open and collaborative atmosphere at IFM and the helpfulness in the semiconductor materials group has made most of my time here at IFM truly joyful.

First of all I would like to express my gratitude to my main supervisor Anelia KakanakovaGeorgieva, not only for the financial support and letting me work in this interesting research area, but also for all guidance, new ideas and suggestions during these years. I am also truly grateful for the encouragement and scientific/financial support from my second supervisor Erik Janzén.

I also would like to thank all co-authors and collaborators; I have very much appreciated the close collaboration together with, Xuan Thang Trinh and Nguyen Tien Son that have carried out the EPR measurements and analysis presented in this work that have strongly contributed to the outcome of this research. I would also like to thank our collaborators at Chalmers, Martin Stattin, Åsa Haglund and Anders Larsson for all their efforts they made on processing of our materials!

All colleagues in the Solaris MOCVD laboratory, Urban Forsberg, Anders Lundskog, Jr-Tai Chen, Chih-Wei Hsu and Xun Li, also deserve big - THANK YOU, for all help in the laboratory and friendship.

I also wish to thank the technical and administrative crew at IFM that have enabled my work to run smoothly over the years. Special thanks go to: Sven Andersson, for helping me to repair the MOCVD reactor, it was fun working with you! I would like to thank Thomas Lingefelt for helping me with the SEM-CL equipment and Eva Wibom for administrative support.

Some other people that I have worked with and that have helped me over the years and that I would like to mention are Kazushiro Nomura, Sin Jhou, Anne Henry and Vanya Darakchieva, thank you!

I would thank all friends at IFM and outside the university, for the years we had together, with nice memorable dinners and cheerful lunch breaks. Special thanks go to Jr-Tai, Ian, Stefano, and Anders that, besides for being good friends, always have been willing to help in the laboratory and to discuss research, which has opened my mind for new ideas!

Finally, express my deepest thankfulness to my family for always being there for me!

To my dear Pitsiri, I don't know what this work would be like without your endless love and support!

Daniel Nilsson

Linköping May 2014 


\section{Contents}

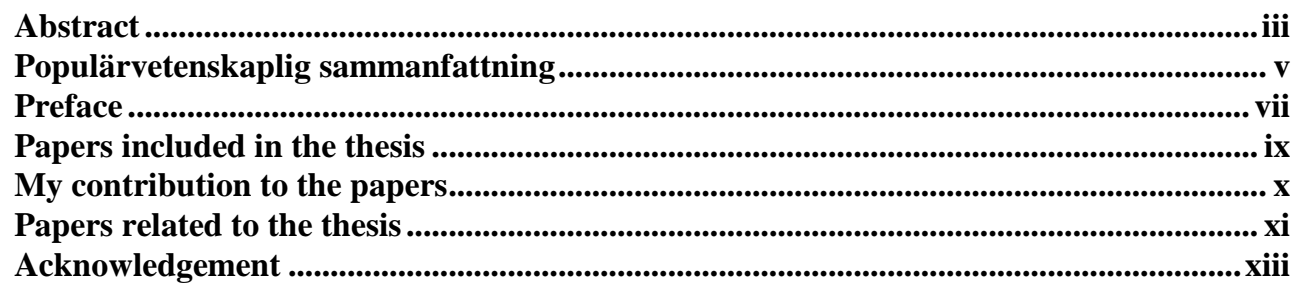

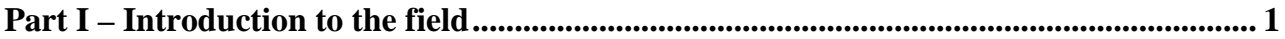

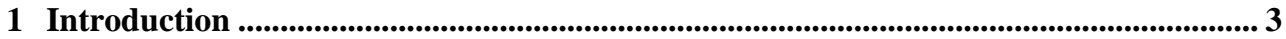

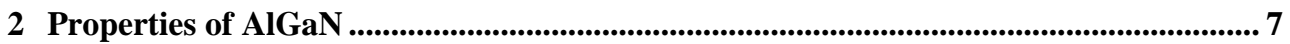

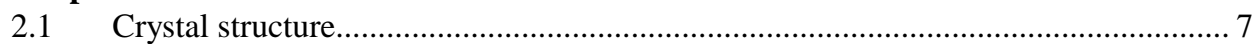

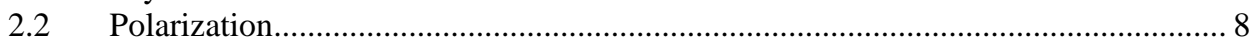

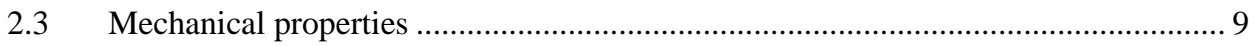

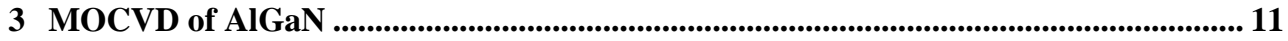

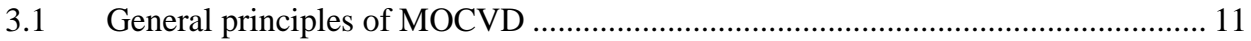

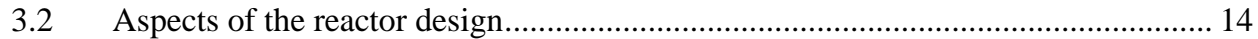

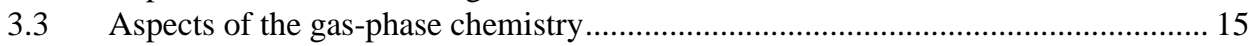

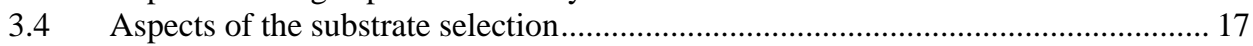

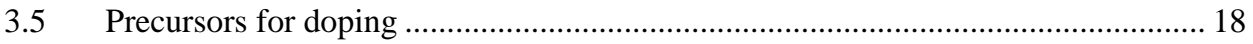

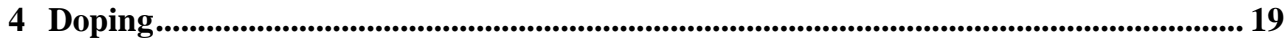

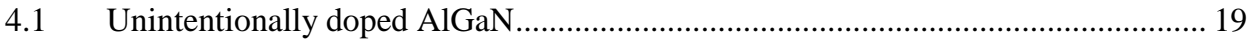

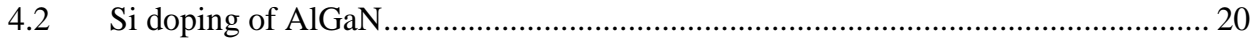

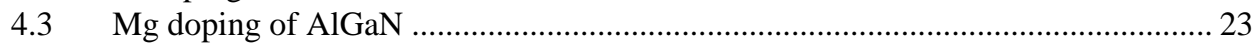

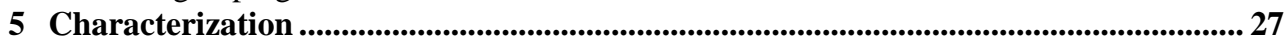

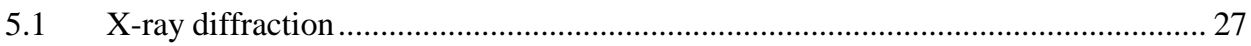

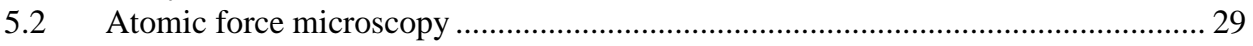

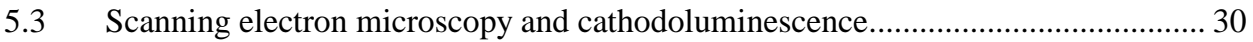

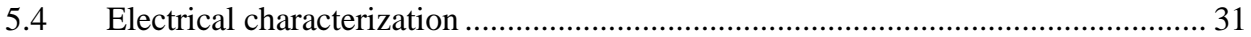

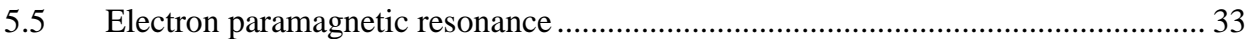

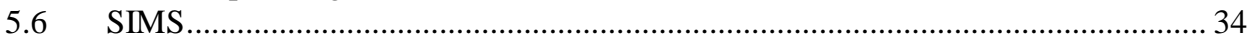

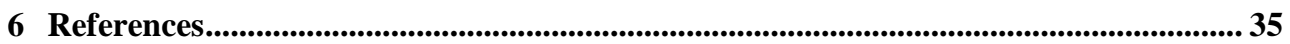

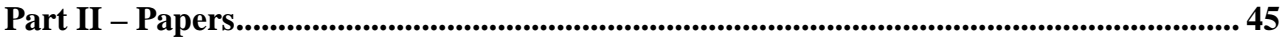

Paper 1-7 



\section{Part I - Introduction to the field}




\section{Introduction}

Wide band-gap semiconductors have been extensively studied the last decades due to their superior material properties, which out-compete the traditional semiconductor materials in many areas of applications such as ultraviolet (UV) optoelectronics [1,2], high temperature microelectronics and high power electronics [3].

Aluminum Gallium Nitride $(\mathrm{AlGaN})$ has a continuous wide direct band-gap $\left(E_{G}\right)$, ranging from $3.5 \mathrm{eV}$ for $\mathrm{GaN}$ to $6.2 \mathrm{eV}$ for $\mathrm{AlN}$, and making this material system most suitable for manufacturing of light-emitting diodes (LEDs) operating in the ultraviolet (UV) spectral region between 210-365 nm. High-Al-content $\mathrm{AlGaN}$ material development has been strongly driven by the fact that deep UV radiation is damaging for bacteria, yeast and viruses [4], which opens up for important fields of applications for deep UV radiation ( $<285 \mathrm{~nm})$, namely, water- and air-purification that have enormous market opportunities [2].

Potential material systems for deep UV optoelectronic applications are listed in Table 1.1. Hexagonal $\mathrm{BN}$ has a wide direct band-gap giving rise to intense luminescence at $215 \mathrm{~nm}$ [5]. However, the different crystal structure and growth conditions have made BN difficult to integrate with the rest of III-Nitrides. Diamond on the other hand is a indirect band-gap semiconductor. Even so, diamond-based deep UV LEDs have been demonstrated, but with a relative low efficiency [6]. The AlGaN and AlInN alloys are the only alloy systems with direct and tunable band-gap in the UV region. Growth of high quality AlInN is very challenging since the optimal growth temperature for $\mathrm{InN}$ is significantly lower $\left(\sim 600^{\circ} \mathrm{C}\right)$ compare to $\mathrm{AlN}$ $\left(\sim 1200-1600{ }^{\circ} \mathrm{C}\right)$ and $\mathrm{GaN}\left(\sim 1100^{\circ} \mathrm{C}\right)[7,8]$. In contrast, high quality AlGaN can be obtained at growth temperatures of $\sim 1100-1200{ }^{\circ} \mathrm{C}$ [9].

In order to utilize the large band-gap of $\mathrm{AlGaN}$ for optoelectronic applications it is essential to control the electrical conductivity by intentionally adding impurities into the crystal lattice in order to form a $p n$-junction. AlN was for a long time considered as an electrical insulator rather than a semiconductor. However, it was shown that both $n$ - and $p$-type conductivity can be obtained in AlN by using Si and Mg doping, respectively, as the first AlN based LED was demonstrated in 2006 [10]. At that time, both the $n$ - and $p$-type conductivity was very poor and the doping is still today one of the most challenging issues in this field in order to achieve high-performance devices.

Table 1.1Band-gap energy and crystal structure of wide band-gap semiconductors with potential for UV optoelectronic applications.

\begin{tabular}{cccc}
\hline & crystal structure & $\begin{array}{c}\mathrm{E}_{\mathrm{G}} \\
(\mathrm{eV})\end{array}$ & $\begin{array}{c}\text { LED wavelength } \\
(\mathrm{nm})\end{array}$ \\
\hline $\mathrm{Al}_{\mathrm{x}} \mathrm{Ga}_{1-\mathrm{x}} \mathrm{N}$ & wurtzite & $3.5-6.2$ (direct) & $\sim 210-365$ \\
$\mathrm{Al}_{\mathrm{x}} \mathrm{In}_{1-\mathrm{x}} \mathrm{N}$ & wurtzite & $0.6-6.2$ (direct) & $\sim 210-2067$ \\
$\mathrm{BN}$ & hexagonal & 6.0 (direct) & 215 \\
Diamond & diamond & 5.5 (indirect) & 235 \\
\hline
\end{tabular}




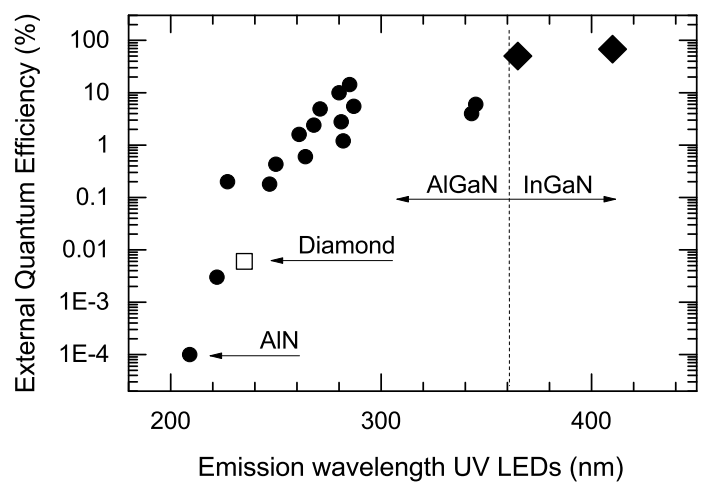

Figure 1.1 External quantum efficiency of state-of-art deep UV LEDs (•) [12-16]and commercially available InGaN based LEDs from Nichia and Soraa ( ) emitting at $365 \mathrm{~nm}$ and $410 \mathrm{~nm}$, respectively [12,17]. State-of-the-art deep UV LED based on Diamond (in-direct band-gap) is given for comparison ()[6].

Deep UV LEDs emitting at 210-280 nm have been demonstrated. However the external quantum efficiency (EQE) decreases for LEDs operating at shorter wavelengths,

Figure 1.1 [11-16]. The commercially available InGaN-based LEDs have a high EQE of about 40-60\% [12] whereas the efficiency drastically decreases for AlGaN-based LEDs and the highest reported EQE for the AlN-based LEDs is very low $\sim 0.0001 \%$ [13]. The drop in EQE is closely linked to the material quality but depends also on the light extraction efficiency and the design of the device [2]. High dislocation densities in epitaxial layers have been shown to negatively influence the device performance [12]. A schematic sketch of AlGaN-based LED is presented in Figure 1.2 and the specific issues posed by each individual layer are indicated.

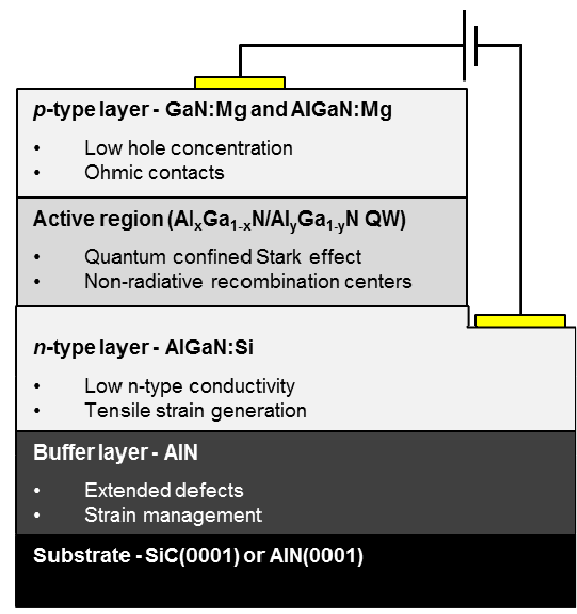

Figure 1.2 Schematic sketch of AlGaN-based LED structure and issues related to each individual layer. 
This thesis focuses on the growth and intentional doping of high-Al-content $\mathrm{Al}_{\mathrm{x}} \mathrm{Ga}_{1-\mathrm{x}} \mathrm{N}$ ( $\mathrm{x}>$ 0.6). The first part of this thesis gives an introduction to the field. The fundamental material properties of AlGaN will be described (chapter 2), and the basic principles of MOCVD are described (chapter 3). The doping properties of $\mathrm{AlGaN}$ are presented and put into a perspective (chapter 4). Finally, brief description of the experimental techniques and methods, which were used during this work is given (chapter 5). The second part of the thesis includes papers 1-7. 


\section{Properties of AlGaN}

\subsection{Crystal structure}

AlGaN has a thermodynamically stable hexagonal wurtzite and a metastable cubic zincblende crystal structure [18]. Both structures are based on tetrahedral atomic coordination where the cation $(\mathrm{Al} / \mathrm{Ga})$ atom is surrounded by four anion $(\mathrm{N})$ atoms. The structures differ in the stacking order of the close packed diatomic planes [Figure 2.1]. The wurtzite structure has a stacking order of $\mathrm{AaBbAa} .$. along the [0001] while the zincblende structure has a stacking order of AaBbCcAa... along the [111]. A, B, C (a, b, c) denote the cation (anion) atoms. One fundamental difference between these two structures is the interaction with the third nearest neighbor, A and a [Figure 2.1(a)]. In the wurtzite structure third nearest neighbor is a pair of the cation and anion atoms which coulomb interaction tends to stabilize the wurtzite structure.

Figure 2.2 (a) shows the tetrahedron that builds up the crystal structure and the characteristic angles $\alpha$ and $\beta$. For ideal tetrahedron the bond length is equivalent for all bonds and $\alpha=\beta \approx$ $109.47^{\circ}$. The wurtzite structure is characterized by the $a$ and $c$ lattice constants and the internal parameter $\mathrm{u}$ defined as the bond distance between the cation and anion atoms divided by the c lattice constant. For AlGaN, the wurtzite structure is distorted from the ideal values as can be seen from the smaller c/a ratio [Table 2.1]. This can be understood as distortion of the bond angles, while the bond lengths of the strong tetrahedral bonds are almost constant, $\sim u c$. Since $\mathrm{N}$ is the most electronegative group $\mathrm{V}$ element the covalent $\mathrm{sp}^{3}$ hybrid bonds in $\mathrm{AlGaN}$ has higher degree of iconicity compared to other III-V semiconductors such as AlGaAs, which results in strong chemical bonds affecting many of the properties of AlGaN.

(a) Wurtzite

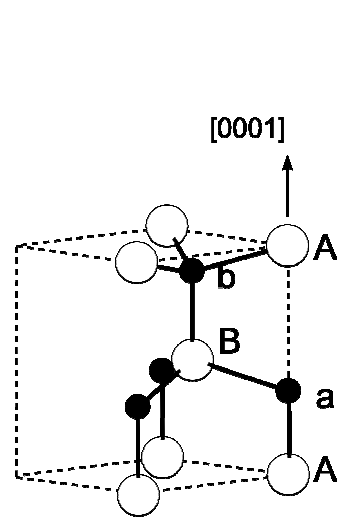

(b) Zincblende

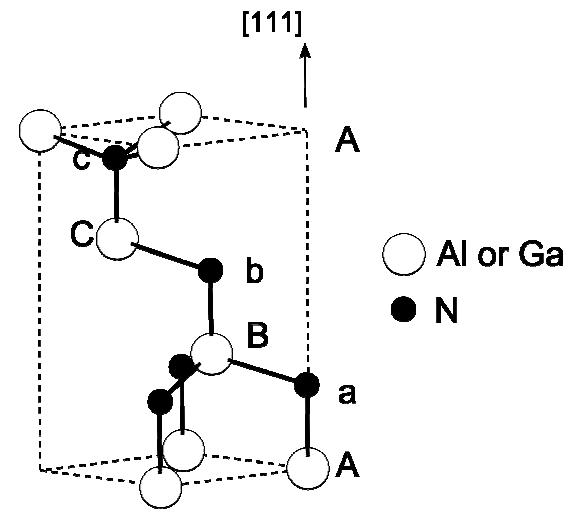

Figure 2.1 Atomic structure and stacking sequence of (a) wurtzite and (b) zincblende crystal structures. The white and black spheres indicate the cation and anion atoms while the bonds are indicated with a solid line. $A, B, C(a, b, c)$ denote the cation (anion) position and indicate the difference in stacking sequence between the two structures. 
(a)

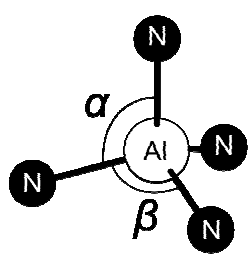

(b)

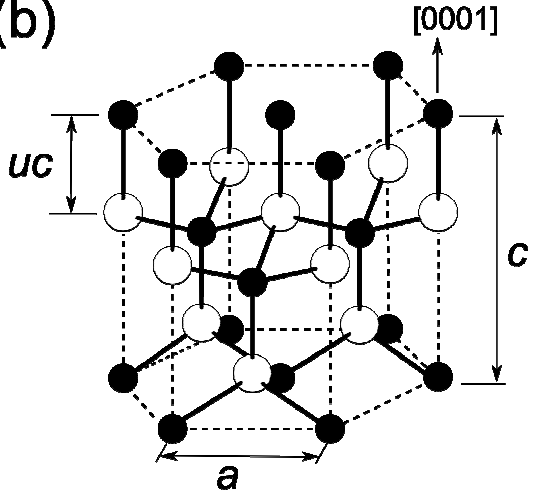

Figure 2.2 (a) tetrahedron with the characteristic angles which are $\alpha=\beta \approx 109.47^{\circ}$ in an ideal tetrahedron and $(b)$ the wurtzite structure with the characteristic $a$ and $c$ lattice constants and the internal parameter $u$ marked in the figure. For AlN the cla ratio is substantially smaller than the ideal value of $c / a \approx 1.633$, which was attributed to the large $\beta$ angle $\left(>109.47^{\circ}\right)$ and with unchanged bond length.

The metastable zincblende structure can be stabilized and grown under certain growth conditions using cubic substrates [19] but the majority of the studies, as well as the work presented in this thesis, treat the hexagonal wurtzite structure.

\subsection{Polarization}

Wurtzite structures have spontaneous polarization along the -c-axis [18]. One consequence of the distorted lattice configuration is that the polarization along the $-\mathrm{c}$-axis strongly enhances compared to what would be expected for the ideal wurtzite structure [20]. This polarization is also affected by strain in the film, an effect that is referred as piezoelectric polarization. The induced polarization will introduce an electrostatic field along the c-axis, which strongly affects the properties of optoelectronic devices. For instance, the electric field leads to separation of the electrons and holes in the quantum well (active layer) in optoelectronic devices grown along the c-axis, which results in low recombination efficiency [21]. Therefore, epitaxial growth along non-polar crystal directions, such as [1 $\overline{1} 00]$ direction, is widely studied [21]. One advantage of the polarization is that the electric field can be utilized for creating polarization induced electron or hole gas [22,23] that can be used to overcome the difficulty in obtaining highly conductive AlGaN. A doping free ("polarization doped") AlGaN-based LED was recently demonstrated [24]. In this work the growth and doping along c-axis oriented substrates was studied.

Table 2.1 Structural parameters of wurtzite AlN and GaN compared to the ideal values for the wurtzite crystal structure at $300 \mathrm{~K}$ [18].

\begin{tabular}{cccccc}
\hline & $a(\AA)$ & $c(\AA)$ & $\mathrm{c} / \mathrm{a}$ & $\mathrm{u}$ & $u c(\AA)$ \\
\hline Ideal & & & $\approx 1.633$ & 0.375 & 1.868 \\
$\mathrm{AlN}$ & 3.112 & 4.982 & 1.601 & 0.380 & 1.893 \\
$\mathrm{GaN}$ & 3.189 & 5.185 & 1.626 & 0.376 & 1.950 \\
\hline
\end{tabular}




\subsection{Mechanical properties}

For small deformations, crystals are elastic and there is a linear relationship between the applied load (stress) and lattice displacement (strain) that is given by Hook's law. Hook's law can be expressed as $\sigma_{\mathrm{ij}}=\mathrm{C}_{\mathrm{ijkl}} \varepsilon_{\mathrm{kl}}$ where $\sigma, \mathrm{C}$ and $\varepsilon$ are the stress, elastic stiffness moduli and strain tensors, respectively [25]. Due to the crystal symmetry the relation between strain and stress tensor in hexagonal crystals can be written using a matrix representation [26]:

$$
\left(\begin{array}{l}
\sigma_{x x} \\
\sigma_{y y} \\
\sigma_{z z} \\
\sigma_{y z} \\
\sigma_{x z} \\
\sigma_{x y}
\end{array}\right)=\left(\begin{array}{cccccc}
C_{11} & C_{12} & C_{13} & 0 & 0 & 0 \\
C_{12} & C_{11} & C_{13} & 0 & 0 & 0 \\
C_{13} & C_{13} & C_{33} & 0 & 0 & 0 \\
0 & 0 & 0 & C_{44} & 0 & 0 \\
0 & 0 & 0 & 0 & C_{44} & 0 \\
0 & 0 & 0 & 0 & 0 & \left(C_{11}-C_{12}\right) / 2
\end{array}\right)\left(\begin{array}{c}
\varepsilon_{x x} \\
\varepsilon_{y y} \\
\varepsilon_{z z} \\
2 \varepsilon_{y z} \\
2 \varepsilon_{x z} \\
2 \varepsilon_{x y}
\end{array}\right),
$$

where $\mathrm{C}_{\mathrm{ij}}$ is the elastic stiffness constants, which have the dimension of pressure. The $\mathrm{x}-$, $\mathrm{y}-$ and z-axis are represented by the [1120 ], [1100], and [0001] directions, respectively.

This gives the useful expressions between stress and strain:

$$
\begin{aligned}
\sigma_{x x} & =C_{11} \varepsilon_{x x}+C_{12} \varepsilon_{y y}+C_{13} \varepsilon_{z z}, \\
\sigma_{y y} & =C_{12} \varepsilon_{x x}+C_{11} \varepsilon_{y y}+C_{13} \varepsilon_{z z}, \\
\sigma_{z z} & =C_{13} \varepsilon_{x x}+C_{13} \varepsilon_{y y}+C_{33} \varepsilon_{z z}, \\
\sigma_{y z} & =2 C_{44} \varepsilon_{y z}, \\
\sigma_{x z} & =2 C_{44} \varepsilon_{x z}, \\
\sigma_{x y} & =\left(C_{11}-C_{12}\right) \varepsilon_{x y}
\end{aligned}
$$

For heteroepitaxial layers grown along [0001] direction, the stress can be assume to be dominated by isotropic biaxial in-plain stress $\left(\sigma_{\mathrm{xx}}=\sigma_{\mathrm{yy}}\right)$ and all other strains are negligibly small. For fully strained epitaxial layers, the external stress is mainly related to the film/substrate interface whereas the layer is free to expand along the [0001] direction $\left(\sigma_{\mathrm{zz}}=0\right)$, giving the following equation:

$$
\sigma_{z z}=0=C_{13} \varepsilon_{x x}+C_{13} \varepsilon_{y y}+C_{33} \varepsilon_{z z} .
$$

Since isotropic in-plain stress is assumed $\left(\varepsilon_{\mathrm{xx}}=\varepsilon_{\mathrm{yy}}\right)$, we can rewrite (2.2) on the form:

$\varepsilon_{z z} \equiv-\frac{2 C_{13}}{C_{33}} \varepsilon_{x x}=R_{B} \varepsilon_{x x}$,

where $\mathrm{R}_{\mathrm{B}}$ is the biaxial strain relaxation coefficient and $\varepsilon_{\mathrm{xx}}$ and $\varepsilon_{\mathrm{zz}}$ are the in-plain and out-ofplain strain, respectively, which are defined as:

$\varepsilon_{x x} \equiv \frac{a-a_{0}}{a_{0}}, \varepsilon_{z z} \equiv \frac{c-c_{0}}{c_{0}}$, 
As we will see in chapter 5.1, the expression above, Eq. (2.3), can be used in order to determine the $\mathrm{Al}$ content in strained $\mathrm{AlGaN}$ layers or the strain in $\mathrm{AlN}$ grown on the c-axis substrates. It is therefore important that the $\mathrm{R}_{\mathrm{B}}$ and the relaxed lattice constants are known. However, in the literature both the relaxed lattice constants and $R_{B}$ widely scatter [27-30]. These quantities are discussed and determined in paper 7. In Table 2.2 the elastic stiffness constants and $\mathrm{R}_{\mathrm{B}}$ are given for GaN and AlN. These values were used in this work to calculate the $\mathrm{Al}$ content of $\mathrm{AlGaN}$ and strain for $\mathrm{AlN}$.

Table 2.2 Elastic stiffness constants for wurtzite AlN and GaN [30]

\begin{tabular}{lcccccc}
\hline & $\begin{array}{c}\mathrm{C}_{11} \\
(\mathrm{GPa})\end{array}$ & $\begin{array}{c}\mathrm{C}_{12} \\
(\mathrm{GPa})\end{array}$ & $\begin{array}{c}\mathrm{C}_{13} \\
(\mathrm{GPa})\end{array}$ & $\begin{array}{c}\mathrm{C}_{33} \\
(\mathrm{GPa})\end{array}$ & $\begin{array}{c}\mathrm{C}_{44} \\
(\mathrm{GPa})\end{array}$ & $\begin{array}{c}\mathrm{R}_{\mathrm{B}} \\
\left(=-2 \mathrm{C}_{13} / \mathrm{C}_{33}\right)\end{array}$ \\
\hline $\mathrm{GaN}$ & 374 & 138 & 101 & 395 & 98 & -0.511 \\
$\mathrm{AlN}$ & 395 & 137 & 107 & 404 & 117 & -0.530 \\
$\mathrm{AlN}$ (This work) & & & & & & $-0.556 \pm 0.021$ \\
\hline
\end{tabular}




\section{MOCVD of AlGaN}

Successful growth of GaN and AlN by metal-organic chemical vapor deposition (MOCVD) was first reported by Manasevit, Erdmann, and Simpson in 1971 [31]. Although the precursors and growth temperature were similar to the one used today, the process was incapable of producing device quality materials due to the low purity of the precursors and low quality of the epitaxial films. The breakthrough for the MOCVD technique came 1978 as Dupuis and Dapkus showed that device quality AlGaAs could be obtained by MOCVD by the demonstration of the first working AlGaAs-based laser diode [32]. This result encouraged the development of various semiconductor material systems for various applications. Nevertheless, it was not until the beginning of the 1990s that the GaN-based material system was mature enough to be used for device applications. The pioneering work, by Akasaki et al.[33], and Nakamura et al. [34], on the development of the MOCVD of the GaN-based material system led to reliable and efficient InGaN based blue light emitting diodes (LEDs) and laser diodes (LDs) [35] that have strongly stimulated the worldwide research efforts and development of the III-Nitrides. Today, basically all epitaxially grown AlGaN-based optoelectronic and electronic device structures on the market are produced using MOCVD. The research focus has now expanded towards the high aluminum and indium containing alloys and nanostructures.

\subsection{General principles of MOCVD}

CVD describes the process where solid material is deposited on a substrate by chemical reactions of vapor phase precursors [36]. The chemical reactions are activated by an external energy source such as heat, plasma or photons. In MOCVD, metal-organic compounds are used as precursors, often together with a hydride gas, such as $\mathrm{AsH}_{3}$ or $\mathrm{NH}_{3}$. It is desirable that the metal-organic precursors are volatile, stable during storage and of high purity [37].

The CVD involves the following sequential steps; (i) transport of precursors to the growth zone, (ii) Gas-phase reactions of the precursors in the hot zone to form reactive intermediates or by-products, (iii) Transport of the precursors and the reactants to the substrate, (iv) adsorption of reactants on the substrate, (v) surface diffusion, nucleation and surface reactions on the surface leading to the growth, and (vi) desorption and transport of by-products away from the surface [36].

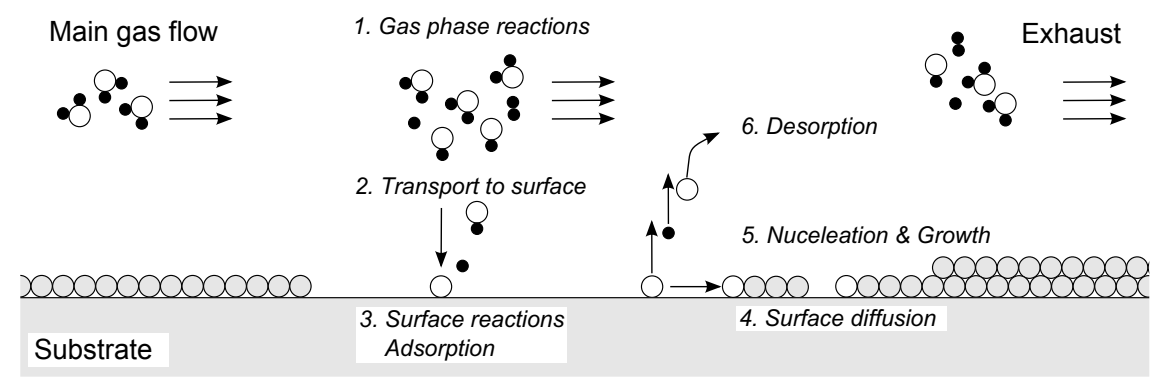

Figure 3.1 Schematic view of the CVD process. 
MOCVD systems normally operate at pressures in the range of a few millibars up to atmospheric pressure. At these pressures the molecules are close enough to meet and interact which means that the gas can be described by the laws of gas dynamics. In order to control the growth, the MOCVD reactor is designed to keep a laminar gas flow above substrate i.e. the fluid flows in parallel layers above the substrate with no mixing perpendicular to the flow direction. In contrast, turbulent gas flows are characterized by chaotic flow patterns that must be avoided to control a smooth distribution of reactant on the substrate.

In the laminar flow regime, the transfer of the reactants to the substrate happens through gas phase diffusion. The velocity profile of gas flowing over a flat plate is show in Figure 3.2. The velocity of the gas at the reactor walls is zero, due to the frictional forces at the surface [38], and gradually increases to $\mathrm{u}_{0}$ far away from the walls. The layer, for which the gas velocity is lower than $\mathrm{u}_{0}$, is defined as the boundary layer, and its thickness $\delta(\mathrm{x})$ is inversely proportional to the square root of the gas velocity:

$$
\delta(x) \propto \sqrt{\frac{v x}{u_{0}}},
$$

where $v$ is the kinematic viscosity of the gas and $x$ is the horizontal position along the plate and $u_{0}$ is the velocity of the gas at infinite distance above the plate. Thus the thickness of the boundary layer can be controlled by the gas velocity and the viscosity of the carrier gas. The boundary layer is of importance for the growth since the molecules and radicals need to diffuse through this layer to react on the surface and contribute to the growth.

The growth rate in thermal CVD is determined by several factors and can be generalized into three limiting modes according to different temperature regimes as illustrated in Figure 3.3:

(1) At low growth temperatures the growth rate decreases exponentially with the reciprocal process temperature $(1 / \mathrm{T})$. In this temperature region the growth rate is limited by the reaction kinetics, namely the slowest reaction in the gas phase or at the surface. The slope of the curve gives the activation energy for the rate limiting process. Since the growth rate is sensitive to the process conditions in this growth window it is challenging to control the growth and get reproducible results over time.

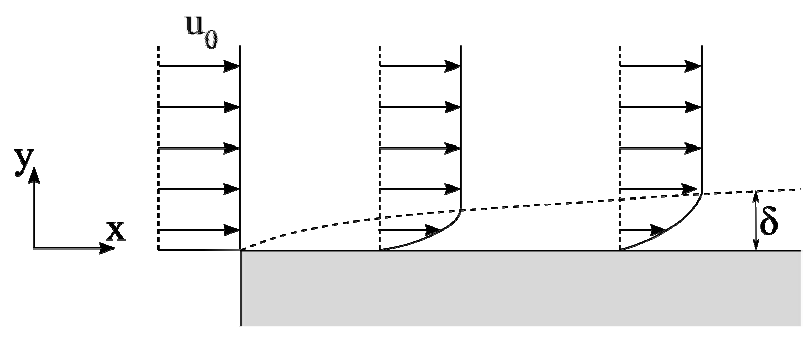

Figure 3.2 Profile of the gas velocity above a flat plate and the formation of a boundary layer that is marked with a dashed line. $u_{0}$ is the undisturbed gas velocity and $\delta(x)$ is the thickness of the boundary layer. 
(2) At medium growth temperatures the growth rate becomes insensitive to the growth temperature. In this region the growth rate is limited by the transport of the reactants to the surface and is therefore called, transport limited growth (or diffusion limited growth). By increasing the precursor concentration or by reducing the thickness of the boundary layer the growth rate can be well controlled and giving reproducible results. (3) At very high growth temperatures the growth rate decreases which can be due to several of factors such as decomposition of the film, parasitic reactions between the precursors in gas phase and desorption of precursors from the surface.

In the mass transport limited regime the growth rate is limited by the diffusion of reactants through the boundary layer. The flux, J, of reactants that diffuse trough the boundary layer can be expressed as,

$J=\frac{D\left(P-P_{i}\right)}{R T \delta} \propto$ Growth rate,

where $P$ is the partial pressure of reactant in the gas phase and $P_{i}$ is the partial pressure at the interface. $T$ is the temperature at the substrate, $D$ is the diffusion coefficient of the reactant in the carrier gas and $R$ is the gas constant. The growth rate is proportional to the flux $\mathrm{J}$ in the mass transport limited growth region. Therefore, in principle, the growth rate can be increased by reducing the pressure since this will reduce the boundary layer [Eq. (3.1)] and increase the diffusivity (D).

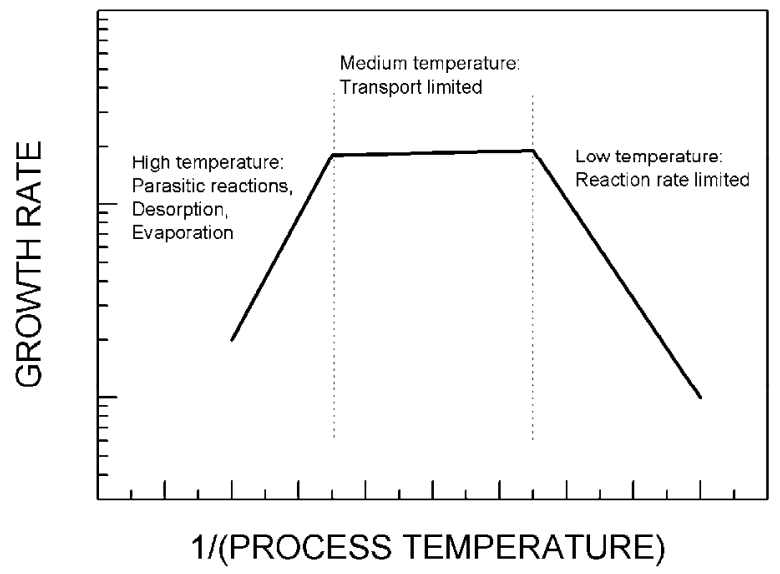

Figure 3.3 Different growth regimes as function of reciprocal process temperature. 


\subsection{Aspects of the reactor design}

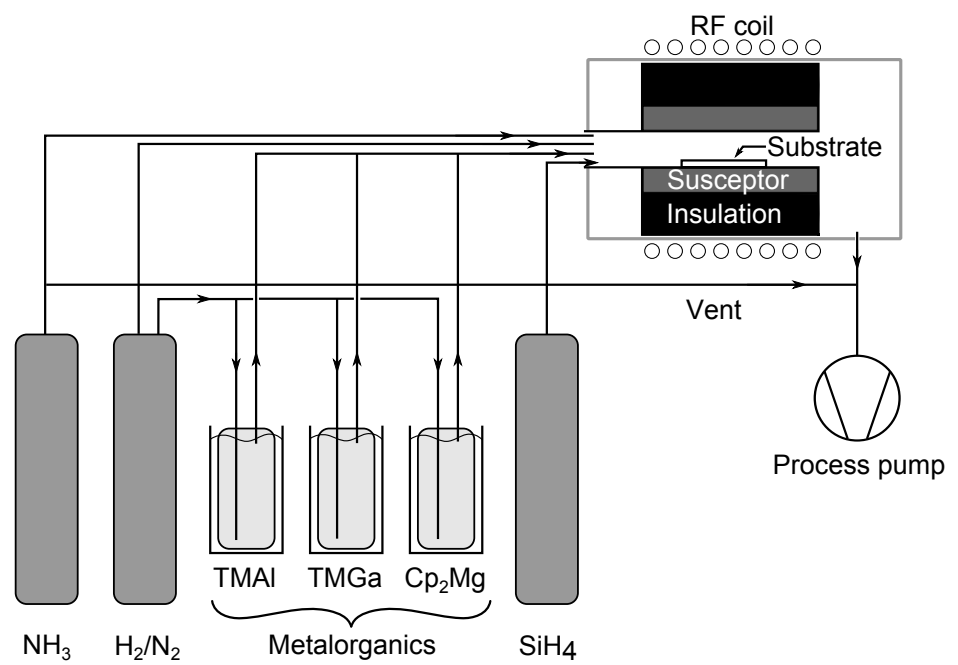

Figure 3.4 Schematic of a horizontal how-wall MOCVD system.

The MOCVD system [Figure 3.1] can be divided into three main subsystems, gas delivery system, pump system and heating system, which are shortly presented below:

The gas delivery system controls the supply of precursors to the growth chamber. The metalorganic precursors are stored in stainless steel containers, called bubblers, which are kept in a thermostat bath where the temperature of the bath controls the vapor pressure of the metalorganics. The carrier gas flows through the liquid metal-organics, and deliver the metalorganic compound to the hot zone inside the growth chamber where the growth takes place. The gas flows are precisely controlled by mass flow controllers (MFCs) and pneumatic valves that that can accurately switch the gas flow from the growth chamber to the vent. The precise control allows growth of atomically flat and abrupt heterostructures.

In the pump system, the pressure in the growth chamber is measured by a pressure gauge and the pumping speed regulates by a valve in order to keep a constant pressure in the cell. Before each run a turbo pump can evacuate the growth chamber in order to reduce the amount of residual vapors and to ensure that the growth chamber is leak tight.

Finally, there is heating system that has a water cooled radio-frequency (RF) coil that inductively heats the graphite susceptor to a certain growth temperature. A pyrometer measures the temperature in order for the system to regulate a stable process temperature. Porous graphite purged with nitrogen is used as an insulator in order to effectively heat the susceptor and to protect the quartz tube from the heat. 
(a)

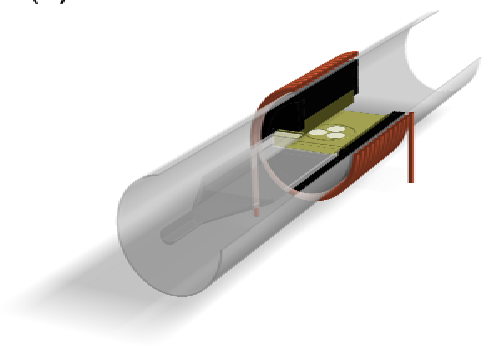

(b)

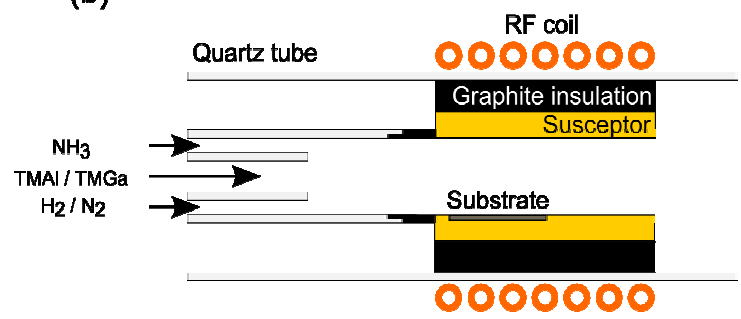

Figure 3.5 (a) Drawing of the horizontal hot-wall MOCVD camber (b) Cross sectional sketch of the growth camber including the up-stream quartz liners and the precursors used for the growth of AlGaN.

In this work a horizontal gas flow hot-wall MOCVD reactor (GaN VP508GFR, Aixtron AB) that has a growth capacity of $1 \times 4$ " (alternatively $3 \times 2$ ") wafers per growth run has been used [39]. The hot-wall MOCVD is new concept for III-nitride growth that was originally designed for growth of $\mathrm{SiC}$ [40]. In the hot-wall MOCVD system the susceptor is wrapped around the substrate as can be seen in Figure 3.5. The heating of the hot-wall MOCVD system gives more uniform heat profiles in gas-phase compared to a cold wall reactor. This leads to a more efficient cracking of the precursors and reduced thermal gradients that will introduce less wafer-bowing [41]. Since the system was developed for $\mathrm{SiC}$ growth, which is usually performed at much higher temperatures, compared to the III-Nitrides. Thus the concept of hotwall MOCVD makes it possible to study growth of III-Nitrides in a very wide temperature range $700-1600{ }^{\circ} \mathrm{C}$. Particularly, high growth temperatures of $1600^{\circ} \mathrm{C}$ benefit achievement of high-quality AlN layers [8].

The MOCVD growth of AlGaN is challenging since the strong Al-N bond induces a low surface mobility of $\mathrm{Al}$ containing species [9]. In order to obtain flat surface morphologies, high growth temperatures are needed to facilitate the surface diffusion. Heteroepitaxial GaN layers with atomically smooth surfaces have been obtained using a growth temperature between $\sim 1000-1100{ }^{\circ} \mathrm{C}$ [42] while the optimized growth temperature for AlN is much higher $\left(>1200{ }^{\circ} \mathrm{C}\right)[8,43]$. Very high quality epitaxial AlN layers were obtained on $6 \mathrm{H}-\mathrm{SiC}$ substrate using a process temperature of $1500-1600{ }^{\circ} \mathrm{C}$ [8]. Since most conventional MOCVD reactors cannot reach such high growth temperatures, sophisticated growth schemes have been developed where the TMAl and $\mathrm{NH}_{3}$ precursors are pulsed in alternating sequences, referred as pulsed atomic-layer deposition $[44,45]$. This technique has been shown to produce high quality films at a relative low growth temperature of $<1200{ }^{\circ} \mathrm{C}[46,47]$.

\subsection{Aspects of the gas-phase chemistry}

Metal-organic precursors such as trimethylaluminum (TMAl or $\left(\mathrm{CH}_{3}\right)_{3} \mathrm{Al}$ ) and trimethylgallium (TMGa or $\left.\left(\mathrm{CH}_{3}\right)_{3} \mathrm{Ga}\right)$ ) together with ammonia $\left(\mathrm{NH}_{3}\right)$ are used as precursors in the MOCVD of AlGaN. The metal-organic precursors are diluted in large flows of purified hydrogen $\left(\mathrm{H}_{2}\right)$ and/or nitrogen $\left(\mathrm{N}_{2}\right)$ that act as carrier gases and deliver the metal-organic precursors to the heated growth zone as shown in Figure 3.5 (b). 
The epitaxial growth of AlGaInN by MOCVD includes the transport of ammonia $\left(\mathrm{NH}_{3}\right)$ gas and the vapor from the liquid trimethylaluminum ( $\left.\mathrm{TMAl}\left(\mathrm{CH}_{3}\right)_{3} \mathrm{Al}\right)$ ), trimethylgallium (TMGa $\left.\left(\mathrm{CH}_{3}\right)_{3} \mathrm{Ga}\right)$ ) or solid trimethylindium (TMIn $\left.\left(\mathrm{CH}_{3}\right)_{3} \mathrm{Ga}\right)$ ) metal-organic sources to the growth chamber and the heated substrate by carrier gas in form of nitrogen $\left(\mathrm{N}_{2}\right)$ and/or hydrogen $\left(\mathrm{H}_{2}\right)$ [48]. Other metal-organics such as triethylgallium (TEGa $\left.\left(\mathrm{C}_{2} \mathrm{H}_{5}\right)_{3} \mathrm{Ga}\right)$ ) can also be used as a $\mathrm{Ga}$ source. Since the ethyl radical is less reactive than the methyl radical a lower $\mathrm{C}$ incorporation can be expected [48].

Both nitrogen and ammonia have a high thermal stability as can be seen from the large dissociation energies of $945 \mathrm{kJmol}^{-1}$ [48] and $435 \mathrm{kJmol}^{-1}\left(\mathrm{H}-\mathrm{NH}_{2}\right)$ [49], respectively. Thus high concentrations of $\mathrm{NH}_{3}$ are needed in order to provide enough nitrogen containing species during growth [50]. An $\mathrm{NH}_{3} /(\mathrm{TMAl}+\mathrm{TMGa})$ ratios of $>1000$ are often used. At high process temperatures and high $\mathrm{NH}_{3}$ flow rates, these parasitic reactions between precursors are facilitated. The overall chemical reaction in MOCVD of III-Nitrides is described in [9]:

$$
\mathrm{M}\left(\mathrm{CH}_{3}\right)_{3}+\mathrm{NH}_{3} \rightarrow \mathrm{MN}+3 \mathrm{CH}_{4}
$$

where $\mathrm{M}$ is a group III metal element ( $\mathrm{Al}, \mathrm{Ga}, \mathrm{In})$. It would be expected that monomethyl radicals and atomic metal atoms form by braking $\mathrm{M}-\mathrm{C}$ bonds, which then can react with nitrogen containing species $\left(\mathrm{NH}_{3}\right.$ and/or $\left.\mathrm{N}_{3-\mathrm{x}}\right)$ at the surface and contribute to the growth [49]. However, in the case of MOCVD of AlN adduct formation between the TMAl and ammonia $\left(\mathrm{M}\left(\mathrm{CH}_{3}\right)_{3}: \mathrm{NH}_{3}\right)$ is difficult to avoid since it forms already at room temperature which strongly influences the reaction pathway [51,52]. The parasitic reactions are more severe during AlN growth as compared with GaN growth and can influence the growth rate and the compositional control of AlGaN [51]. Kinetic models of the AlN growth process include adduct formation between $\mathrm{TMAl}$ and $\mathrm{NH}_{3}$ that react in the gas phase [51,52]:

$$
\mathrm{Al}\left(\mathrm{CH}_{3}\right)_{3}+\mathrm{NH}_{3} \leftrightarrow \mathrm{Al}\left(\mathrm{CH}_{3}\right)_{3}: \mathrm{NH}_{3}
$$

Methane $\left(\mathrm{CH}_{4}\right)$ elimination occurs according with

$$
\mathrm{Al}\left(\mathrm{CH}_{3}\right)_{3}: \mathrm{NH}_{3} \rightarrow \mathrm{Al}\left(\mathrm{CH}_{3}\right)_{2}: \mathrm{NH}_{2}+\mathrm{CH}_{4}
$$

Finally, $\mathrm{Al}\left(\mathrm{CH}_{3}\right)_{2}: \mathrm{NH}_{2}$ may climb to larger stable oligomer ring species:

$$
\mathrm{nAl}\left(\mathrm{CH}_{3}\right)_{2}: \mathrm{NH}_{2} \rightarrow\left(\mathrm{Al}\left(\mathrm{CH}_{3}\right)_{2}: \mathrm{NH}_{2}\right)_{n} \text {. }
$$

Monomers $(n=1)$ and dimers $(n=2)$ are expected to contribute to the growth while the higher order oligomers $(n>2)$ have a low vapor pressure and are therefore not likely to contribute to the growth but may initiate AIN particles in the gas-phase at high growth temperatures. The large AlN particles are repelled from the hot surface due to the thermophoresis effect and thus strongly reducing the growth efficiency.

It was suggested that the equilibrium of reaction (R3.2) can shift and stabilize TMAl at low $\mathrm{V} / \mathrm{III}$ ratios and thus avoid severe losses by parasitic reactions [53]. Low reactor pressures [51,52] or increase the nitrogen composition in the carrier gas [54] can also improve the growth efficiency. 


\subsection{Aspects of the substrate selection}

In this work growth was performed on both $4 \mathrm{H}-\mathrm{SiC}$ and $\mathrm{AlN}$ substrates. Properties of the common substrates used for AlN epitaxy are summarized in Table 3.1. The SiC substrates are implemented for heteroepitaxial growth because of their large size, extremely good thermal conductivity and variety in electrical conductivity. Moreover, the lattice mismatch to AlN along the basal plane is relative small $(\sim 1 \%)$. compare to other substrates (sapphire $\sim-13 \%$ ) [Table 3.1]. The drawback is it the relatively low band-gap of $\sim 3.2 \mathrm{eV}$ which is not transparent for deep UV radiation.

The lattice mismatch will introduce a misfit dislocation network at the AlN/SiC interface, $[55,56]$. The expected critical thickness for the accumulated misfit strain to relax by creation of misfit dislocation is about $\sim 20 \mathrm{~nm}$ [58]. Strain relaxation of the epitaxial layer during growth by generation of misfit dislocations is expected to occur [59]. In addition, the thermal mismatch between the substrate and the epitaxial layer can cause significant strain in the layer during the cooling [60]. If no additional relaxation occurs during cooling the thermal strain is given by [57]:

$\varepsilon_{\text {thermal }}=\int_{T_{G}}^{T_{R T}} \alpha_{S}(T)-\alpha_{L}(T) d T \approx\left(T_{R T}-T_{G}\right)\left(\alpha_{S}-\alpha_{L}\right)$

Since AlN has a larger thermal expansion coefficient than SiC [Table 3.1], a tensile in-plain stress is introduced during the cooling to room temperature.

Heteroepitaxial growth of AlN also leads to high threading dislocation densities. Large efforts have been made in order to reduce the threading dislocations. However, the material quality of heteroepitaxial AlN is still poor, with high densities of threading dislocations, $10^{8}-10^{10} \mathrm{~cm}^{-3}$. On the other hand, homoepitaxial growth is expected to result in AlN layers with superior crystal quality with threading dislocation densities of the same order as the commercial substrates $10^{2}-10^{4} \mathrm{~cm}^{-3}$ and low residual strain if the growth is properly initiated. High-performance deep UV LEDs $\lambda<280 \mathrm{~nm}$ are obtained by MOCVD on high-quality AlN substrates.

Table 3.1 Lattice parameters and thermal properties of commonly used substrates for AlGaN growth. The lattice misfit is defined as $\left(a_{0 \text { Substate }} a_{0 A I N}\right) / a_{0 A I N}[61]$.

\begin{tabular}{ccccccc}
\hline & structure & $\begin{array}{c}\mathrm{a}_{0} \\
(\AA)\end{array}$ & $\begin{array}{c}\mathrm{c}_{0} \\
(\AA)\end{array}$ & $\begin{array}{c}\text { lattice misfit } \\
\text { with AlN } \\
(\%)\end{array}$ & $\begin{array}{c}\alpha_{\mathrm{a}} \\
\left(10^{-6} /{ }^{\circ} \mathrm{C}\right)\end{array}$ & $\begin{array}{c}\text { Thermal } \\
\text { conductivity } \\
\left(\mathrm{Wcm}^{-1} \mathrm{~K}^{-1}\right)\end{array}$ \\
\hline $\mathrm{Si}$ & diamond & $5.431^{1}$ & - & & $3.9^{1}$ & $1.3^{2}$ \\
$\mathrm{Al}_{2} \mathrm{O}_{3}$ & Rhombohedral & $4.759^{1}$ & $12.991^{1}$ & -13 & $8.31^{1}$ & $0.25^{3}$ \\
$4 \mathrm{H}-\mathrm{SiC}$ & Hexagonal & $3.080^{1}$ & $10.083^{1}$ & 1 & $4.75^{1}$ & $4.9^{2}$ \\
$\mathrm{GaN}$ & wurtzite & $3.189^{4}$ & $5.186^{4}$ & 2.4 & $5.00^{1}$ & $1.3^{2}$ \\
$\mathrm{AlN}$ & wurzite & $3.112^{4}$ & $4.981^{4}$ & 0 & $5.41^{1}$ & $2.85^{2}$ \\
\hline
\end{tabular}

\footnotetext{
${ }^{1}$ Reference [60]

${ }^{2}$ Reference [62]

${ }^{3}$ Reference [63]

${ }^{4}$ Reference [27]
} 


\subsection{Precursors for doping}

Both $n$ and $p$-type conductive AlGaN can be obtained by MOCVD by $\mathrm{Si}$ and $\mathrm{Mg}$ doping, respectively [43]. Silane $\left(\mathrm{SiH}_{4}\right)$ [64] and disilane $\left(\mathrm{Si}_{2} \mathrm{H}_{6}\right)$ [65] gas diluted in $\mathrm{H}_{2}$ have been used as efficient $\mathrm{Si}$ doping sources for high-Al-content $\mathrm{AlGaN}$. $\mathrm{Si}_{2} \mathrm{H}_{6}$ has been shown to decompose at significantly lower temperatures compare to $\mathrm{SiH}_{4}$ which is of advantage due to less strong temperature dependence of the Si incorporation during GaAs growth [66]. Ge is a well-known donor in GaN [67] and has also been demonstrated as dopant for low-Al-content AlGaN [68]. Due to the large size of the Ge atom, the incorporation efficiency is lower compared to $\mathrm{Si} 1000$ times higher flows of $\mathrm{GeH}_{4}$ was needed to achieve similar doping concentration as with $\mathrm{SiH}_{4}$ precursor for $\mathrm{GaN}$ [67].

Biscyclopentadienyl-magnesium $\left(\mathrm{Cp}_{2} \mathrm{Mg}\right)$ is frequently used as the $\mathrm{Mg}$ doping source. $\mathrm{Cp}_{2} \mathrm{Mg}$ is a solid metal-organic precursor. The $\mathrm{Mg}$ doping is also associated with memory effects $[69,70]$ which make it challenging to control sharp doping profiles. In this work $\mathrm{SiH}_{4}$ and $\mathrm{Cp}_{2} \mathrm{Mg}$ were used as doping sources. 


\section{Doping}

Wide band-gap semiconductors have very low intrinsic carrier concentrations and are therefore expected to act as true insulators at room temperature:

$n_{i}=\sqrt{N_{c} N_{V}} \exp \left(-E_{G} / 2 k T\right)$

where $\mathrm{N}_{\mathrm{C}}$ and $\mathrm{N}_{\mathrm{V}}$ are the effective density of states in the conduction and valence band, respectively, $k$ is the Boltzmann constant and $E_{G}$ is the band-gap. However, unintentionally incorporated impurities and native defects, which are present also in the most pure materials, can strongly influence the conductivity of unintentionally doped semiconductors. By reducing the number of electrically active defects, it is possible to control the conductivity by intentionally introducing dopant impurities that incorporate in the crystal lattice. The impurities can form states in the band-gap, which can either be donors that donates electrons to the conduction band or acceptors that accept electrons from the valence band and thus create a hole in the valence band. The free electrons and holes can easily move and conduct current when an electric field is applied. When the conductivity is dominated by free electrons or holes the semiconductor is referred as $n$-type and $p$-type conductive, respectively. Donors (acceptors) that have an energy level close to the conduction (valence) band are denoted as shallow donors (acceptors). The ionization energy $\left(E_{d}\right)$ of shallow dopants is typically in the order of the thermal energy at room temperature, $\mathrm{kT} \approx 26 \mathrm{meV}$, which results in high free electron and hole concentrations.

For wide band-gap semiconductors it is usually difficult to obtain both $n$ - and $p$-type conductivity due to amphoteric defects that limit the maximum number of electrically active and uncompensated dopants [71]. There is also a tendency for intrinsic defects and impurities to form electrically active states in the band gap that affect the conductivity. If these are deep states, only a small fraction are ionized at room temperature leading to low room temperature conductivity or compensation of more shallow states. For high-Al-content AlGaN and AlN with their remarkably wide band-gaps of up to $6.2 \mathrm{eV}$, it is truly challenging to control both the $n$-type and $p$-type conductivity. In this chapter the basic properties of doping and important results from the literature are reviewed with the purpose to put our results and work into a relevant context.

\subsection{Unintentionally doped AIGaN}

The first step in order to control the doping process is to understand and control the unintentional background doping in $\mathrm{AlGaN}$. Unintentionally doped $\mathrm{GaN}$ is, despite its large band-gap of $3.4 \mathrm{eV}$, n-type conductive even in high purity materials [72]. Typically, incorporation of deep acceptors such as Fe [73] or C [74] is needed in order to render GaN insulating. The nitrogen vacancy $\left(\mathrm{V}_{\mathrm{N}}\right)$ was originally considered as the main source of the unintentional n-type conductivity in GaN [75] and theoretical calculations indeed suggested that $\mathrm{V}_{\mathrm{N}}$ acts as a shallow donor for $\mathrm{GaN}$ but also that its formation energy was considered too high for $\mathrm{V}_{\mathrm{N}}$ to be abundant in high concentrations under normal growth conditions [76]. Instead the n-type conductivity of unintentionally doped $\mathrm{GaN}$ was attributed to the shallow residual $\mathrm{O}$ and $\mathrm{Si}$ impurities that were unintentionally incorporated during growth [76]. 
Oxygen easily reacts with $\mathrm{Ga}$ and especially $\mathrm{Al}$ and are therefore typically incorporated at high concentrations during growth of AlGaN [77]. Typically, $\mathrm{O}$ is present in form of residual water incorporated during wafer loading or introduced by the carrier or precursor gases. Oxygen can also originate direct from the quartz tube $\left(\mathrm{SiO}_{2}\right)[48]$.

In contrast to $\mathrm{GaN}$, unintentionally doped $\mathrm{Al}_{\mathrm{x}} \mathrm{Ga}_{1-\mathrm{x}} \mathrm{N}$ is normally resistive or insulating at high $\mathrm{Al}$ contents [78]. The different behavior compared to $\mathrm{GaN}$ was attributed to the $\mathrm{O}$ donor that is believed to become a deep donor at $\mathrm{Al}$ contents above $\mathrm{x}>0.3[79,80]$ or by the much lower formation energy for cation vacancy related complexes ( $\mathrm{V}_{\mathrm{III}}$-complexes) that act as deep acceptors and may therefore be abundant in unintentionally $\mathrm{AlGaN}$ and lead to compensation of free carriers $[76,81,82]$. More recent publications observed that the $\mathrm{O}$ impurities improved the conductivity in $\mathrm{Si}$ doped $\mathrm{Al}_{0.6} \mathrm{Ga}_{0.4} \mathrm{~N}$ [83] and in unintentionally doped $\mathrm{Al}_{0.67} \mathrm{Ga}_{0.33} \mathrm{~N}$ for which a donor activation energy of $\mathrm{E}_{\mathrm{d}} \sim 90 \mathrm{meV}$ was measured [84].

Unintentionally doped $\mathrm{Al}_{\mathrm{x}} \mathrm{Ga}_{1-\mathrm{x}} \mathrm{N}(\mathrm{x}>0.6)$ layers grown in this work, have a low conductivity which is not measurable (donor concentration $<10^{15}-10^{16}$ ). Both the $\mathrm{O}$ and $\mathrm{C}$ concentrations in these layers were typical at the detection limit $\left(\sim 2 \times 10^{17} \mathrm{~cm}^{-3}\right)$ as measured by secondary ion mass spectroscopy (SIMS). These are good starting conditions for intentional doping.

\subsection{Si doping of AlGaN}

A simple hydrogenic model can describe the shallow substitutional donor and its properties where the ionization energy of the donor impurity $\left(\mathrm{E}_{\mathrm{d} 0}\right)$ can be calculated by [38]:

$$
E_{d 0}=13.6 \frac{m_{e}^{*} / m_{0}}{\varepsilon_{r}^{2}} \mathrm{eV}
$$

Here $m_{0}^{*}$ is the effective mass of the free electron in the conduction band and $\varepsilon_{r}$ is the relative dielectric constant. Thus the ionization energy of the donor reminds of the ionization energy of the hydrogen atom $(\sim 13.6 \mathrm{eV})$ which is then corrected by the effective mass of the electron and the reduced Coulomb interaction introduced by the dielectric medium.

At increased donor concentrations the donor impurity potential starts to overlap and donor ionization, $\mathrm{E}_{\mathrm{d}}$ decreases. At a critical doping concentration $\left(N_{\text {critical }}\right)$ the material undergoes a transition from insulator-to-metal which is also called the Mott transition [85]. This implies that the impurity binding energy vanishes $\left(E_{d}=0\right)$ and the electrons are free to move at any temperature. For shallow donors this transition can be expressed as,

$$
N_{\text {critical }} \approx\left(\frac{0.25}{a_{B}^{*}}\right)^{3} \approx\left(\frac{4.72 \times 10^{7} m_{e}^{*} / m_{0}}{\varepsilon_{r}}\right)^{3} \mathrm{~cm}^{-3},
$$

where $\mathrm{a}_{\mathrm{B}}$ is the Bohr radius of the donor in the ground state given by $a_{B}^{*}=0.53 \varepsilon_{r} /\left(m_{e}^{*} / m_{0}\right)$ $\AA$. The reduced $\mathrm{E}_{\mathrm{d}}$ with increased donor concentration $\left(\mathrm{N}_{\mathrm{D}}\right)$ can be expressed by:

$$
E_{d}=E_{d 0}\left(1-\left(N_{D} / N_{\text {critical }}\right)^{1 / 3}\right)
$$


The $N_{\text {critical }}$ and $E_{d 0}$ for shallow substitutional donors for AlN and GaN calculated from Eq. (4.2-4.3) are given in Table 4.1.

For high doping levels the activation energy is expected to vanish due to the insulator-metal transition at doping concentrations of $[\mathrm{Si}]=\mathrm{N}_{\text {critical }} \approx \operatorname{mid} 10^{18} \mathrm{~cm}^{-3}$ for $\mathrm{AlGaN}$ [

Table 4.1] which is in good agreement with published data for $\mathrm{GaN}$ and low Al-content AlGaN [86,87]. For non-degenerate $\left(\mathrm{N}_{\mathrm{D}}<\mathrm{N}_{\text {Critical }}\right)$ semiconductors the electron concentration in the conduction band can be roughly estimated using the following expression [38]:

$n \approx \sqrt{\frac{N_{D} N_{C}}{2}} \exp \left(\frac{-E_{d}}{2 k T}\right)$

For $\mathrm{GaN}, n$-type conductivity is easily obtained by substituting, $\mathrm{Ga}$ with $\mathrm{Si}$ ( $\mathrm{Si}_{\mathrm{Ga}}$ ) [67], $\mathrm{Ge}$ $\left(\mathrm{Ge}_{\mathrm{Ga}}\right)$ [67] or $\mathrm{Se}\left(\mathrm{Se}_{\mathrm{Ga}}\right)$ [92] or substituting $\mathrm{N}$ with $\mathrm{O}\left(\mathrm{O}_{\mathrm{N}}\right)$ [93]. All these donors are found to form shallow, hydrogen-like, donors with low activation energy in the range of $\sim 30 \mathrm{meV}$ which is in good agreement with effective mass theory. Since Si easily incorporates into $\mathrm{AlGaN}$ it is often used as the n-type dopant in this and other III-V alloy systems.

We note that this simple hydrogenic model described above in Eq. (4.2-4.3) gives values that are close to the values experimentally measured by electrical transport measurements (measured in low doped material) for Si doped GaN but not for AlN [

Table 4.1] indicating that the Si may not be a simple substitutional shallow donor for AlN, a topic which is treated in paper 4. We found that for an $\mathrm{Al}$ content up to $\mathrm{x} \sim 0.8$, Si behaves similar to a shallow donor and can be described to a reasonable agreement with equation (Eq. $(4.3-4.5))$ [87].

By using the photoluminescence spectroscopy the Si donor ionization energy in GaN and AlN was determined to $\sim 30 \mathrm{meV}$ [90] and $\sim 63 \mathrm{meV}$ [91], respectively, which is in close agreement with effective mass theory. Taking into account the reduction of the donor ionization energy due to high doping effects Eq. (3), such shallow doping levels are expected to result in efficient Si doping in the entire AlGaN compositional range.

Table 4.1 Basic electronic properties of GaN and AlN and the donor ionization energy determined from effective-mass theory (EMT) and electrical transport measurement by Hall.

\begin{tabular}{ccccccc}
\hline & $\begin{array}{c}n_{i} \\
\left(\mathrm{~cm}^{-3}\right)\end{array}$ & $\varepsilon_{r}$ & $m_{e}^{*} / m_{0}$ & $\begin{array}{c}N_{\text {critical }} \\
\left(\mathrm{cm}^{-3}\right)\end{array}$ & $\begin{array}{c}\mathrm{E}_{\mathrm{d} \mathrm{Si}} \\
\mathrm{EMT} \\
(\mathrm{meV})\end{array}$ & $\begin{array}{c}\mathrm{E}_{\mathrm{d} \mathrm{Si}} \\
\text { Hall } \\
(\mathrm{meV})\end{array}$ \\
\hline $\mathrm{GaN}$ & $\sim 10^{-10 \mathrm{a})}$ & $8.9^{\mathrm{a})}$ & $0.20^{\mathrm{b})}$ & $1 \times 10^{18 \mathrm{c})}$ & $\sim 34^{\mathrm{c})}$ & $30.7^{\mathrm{d})}$ \\
$\mathrm{AlN}$ & $\sim 10^{-33 \mathrm{a})}$ & $8.5^{\mathrm{a})}$ & $0.32^{\mathrm{b})}$ & $6 \times 10^{18 \mathrm{c})}$ & $\sim 60^{\mathrm{c})}$ & $282^{\mathrm{e})}$ \\
\hline
\end{tabular}

\footnotetext{
a) Reference [88]

b) Reference [89]

${ }^{\text {c) }}$ Reference [Eq. (4.3)]

${ }^{\text {d) }}$ Reference [90]

${ }^{\text {e) }}$ Reference [91]
} 
However, electrical transport measurements of Si doped AlGaN layers show significantly reduced conductivity as the $\mathrm{Al}$ composition increases above 0.8 [64,94-96]. The resistivity in high-Al-content $\mathrm{AlGaN}$ was found to increase from $0.026 \Omega \mathrm{cm}$ to $2.62 \Omega \mathrm{cm}$ as the Alcontent increased from $\mathrm{x} \sim 0.82$ to $\mathrm{x} \sim 0.95$ [96]. It was shown that the $\mathrm{Si}$ activation energy drastically increased and activation energies between 282-312 meV were determined for low Si doped AlN assuming a single shallow donor state [97]. The reason for this behavior has been controversial. Despite the large increase in Si activation energy at high Al contents it was suggested that $\mathrm{Si}$ acts as shallow donor in the entire compositional range and that the observed decrease in conductivity was also related to unintentional $\mathrm{O}$ and $\mathrm{C}$ doping $[94,95]$ and formation of cation vacancies $\left(\mathrm{V}_{\mathrm{III}}\right)[76]$.

Another explanation for the drastic decrease in n-type conductivity is that $\mathrm{Si}$ and $\mathrm{O}$ transform to a deep donor at high-Al-content AlGaN. Deep donors in other III-V semiconductor material systems, such as $\mathrm{Al}_{\mathrm{x}} \mathrm{Ga}_{1-\mathrm{x}} \mathrm{As}$ doped with $\mathrm{Si}$, have been extensively studied [98]. Deep metastable donor states are observed in $\mathrm{Al}_{\mathrm{x}} \mathrm{Ga}_{1-\mathrm{x}} \mathrm{As}: \mathrm{Si}$ at alloy compositions between $0.2<\mathrm{x}<0.8$, which results in properties characterized by a high degree of self-compensation and persistent photo-conductivity at low temperatures. Similar characteristics were reported for $\mathrm{Al}_{\mathrm{x}} \mathrm{Ga}_{1-\mathrm{x}} \mathrm{N}$ with an alloy composition above $\mathrm{x}>0.52$ [78,99]. Based on theoretical calculations a widely accepted model that explains the experimental observations has been proposed for AlGaAs [100], where the shallow substitutional donor configuration coexist with a distorted donor configuration. The distorted donor, referred as a DX-center, is formed by breaking one of the tetrahedral bonds and trapping of one additional electron whereby it undergoes a large lattice relaxation. The name "DX" was chosen since it was postulated that the defect was related to the donor $\mathrm{D}$ together with another unknown constituent $\mathrm{X}$ as the DX-center was described for the first time [101].

The formation of the DX-center can be described by [103]:

$2 d_{0} \leftrightarrow d^{+}+D X^{-}+U$

where $\mathrm{d}_{0}$ is shallow donor state and $\mathrm{U}$ is the correlation energy that mainly contain contribution from the Columbic repulsion between the captured electrons and the lattice distortion energy.

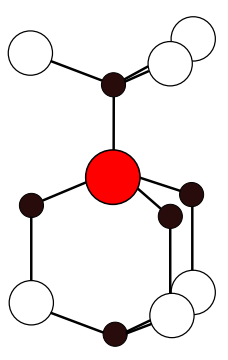

(a) Si substitutional

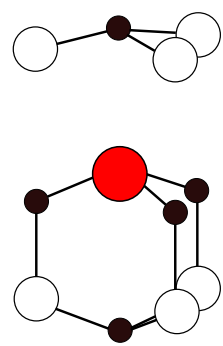

(b) Si DX

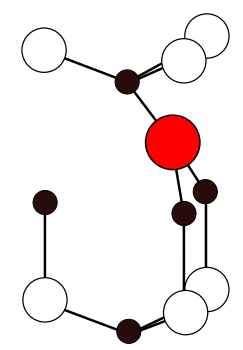

(c) $\mathrm{Si} \mathrm{DX}_{2}$

Figure 4.1Schematic view of (a) the substitutional Si donor, (b) Si DX1 configuration $(U=-0.27 \mathrm{eV})$ and $(\mathrm{c})$ Si DX2 $(U=-0.06 \mathrm{eV})$ [102]. 
If $U$ is negative (thus when the Columbic repulsion energy is lower than the lattice relaxation) the DX-center becomes stable and the center is therefore often referred as a negative-U center [Figure 4.1]. The properties of a shallow to DX-center transition via a large lattice relaxation can be illustrated by a configuration coordinate diagram shown in Figure 4.2 [78].

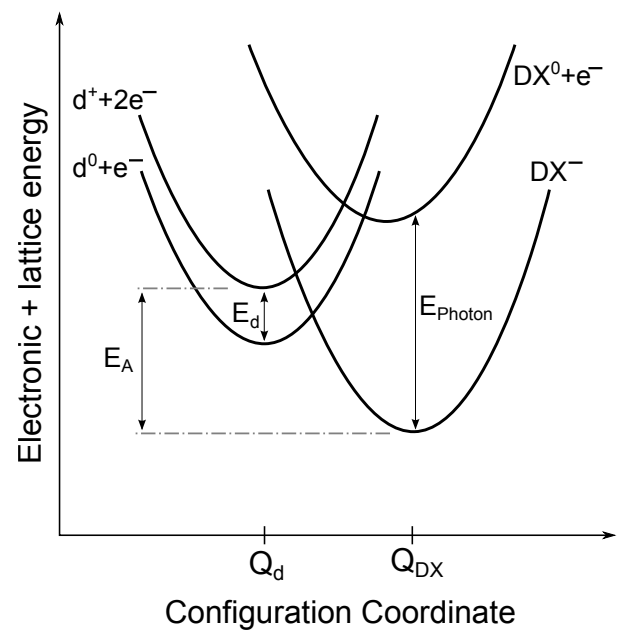

Figure 4.2 Configuration coordinate diagram describing the behavior of a DX center for Si doped AlN [78]. $E_{d}$ is the shallow donor ionization energy, $E_{A}$ is the thermal activation energy of the Si donor and $E_{\text {photon }}$ is the photoionization energy.

Recent $a b$ initio calculations suggest that $\mathrm{Si}, \mathrm{O}$, and Ge form stable DX-centers in AlGaN $[102,104]$. It was found that $\mathrm{Si}$ was the most efficient donor forming a DX-center first at Alcontents above $\mathrm{x} \approx 0.94$ [104]. In paper 4 a drastic increase in the activation energy of the $\mathrm{Si}$ donor was observed for AlGaN with high aluminum contents $(x>0.8)$. It was suggested that the $\mathrm{DX}^{-}$center becomes drastically deeper at this alloy compositions. Bellow this alloy composition efficient Si doping was obtained.

\subsection{Mg doping of AlGaN}

$\mathrm{Mg}$ is the most widely used dopant for $p$-type doping and so far the only acceptor that was proven to produce controlled $p$-type conductive AlGaN. Recent theoretical calculations suggest that $\mathrm{Mg}$ is the shallowest acceptor of the group II elements [105]. However, Mg has a rather high activation energy, about $200 \mathrm{meV}$ for GaN [106] and $~ 500-630 \mathrm{meV}$ for AlN $[10,107]$, which results in a low doping efficiency. In order to obtain appropriate $p$-type conductivity a very high $\mathrm{Mg}$ doping concentration is needed. In $\mathrm{AlGaN}$ there are about $\sim 5 \times 10^{22} \mathrm{~cm}^{-3}$ group III lattice sites available, giving a fundamental doping limit in the order 
Table 4.2 Results obtain for Mg doping of high-Al-content $A l_{x} G a_{1-x} N$ in this work compared to the reported results.

\begin{tabular}{|c|c|c|c|c|}
\hline \multirow{2}{*}{$\begin{array}{c}\mathrm{Al}_{\mathrm{x}} \mathrm{Ga}_{1-\mathrm{x}} \mathrm{N}: \mathrm{Mg} \\
\mathrm{x}\end{array}$} & \multirow{2}{*}{$\begin{array}{l}{[\mathrm{Mg}]} \\
\left(\mathrm{cm}^{-3}\right)\end{array}$} & \multicolumn{2}{|c|}{ Resistivity $(\Omega \mathrm{cm})$} & \multirow[t]{2}{*}{ Reference } \\
\hline & & As-grown & Annealed & \\
\hline \multicolumn{5}{|l|}{ This work: } \\
\hline 0.60 & $3 \times 10^{19}$ & $>10^{7}$ & 60 & \\
\hline 0.70 & $2 \times 10^{19}$ & $>10^{7}$ & 2000 & \\
\hline 0.85 & $2 \times 10^{19}$ & $>10^{7}$ & 7000 & [paper5] \\
\hline \multicolumn{5}{|l|}{ Literature: } \\
\hline 0 & $2 \times 10^{20}$ & & 1 & {$[106]$} \\
\hline 0.45 & $2 \times 10^{19}$ & & 8 & [69] \\
\hline 0.70 & $3 \times 10^{19}$ & & 47 & [114] \\
\hline 0.70 & $1 \times 10^{20}$ & & 100000 & [112] \\
\hline 1.00 & $2 \times 10^{19}$ & & $\sim 10^{7}$ & {$[10,115]$} \\
\hline
\end{tabular}

of $10^{20} 10^{21} \mathrm{~cm}^{-3}$ before alloying. It was suggested that the doping is limited by the solubility and the formation of $\mathrm{Mg}_{3} \mathrm{~N}_{2}$ [76]. A drastic decrease in carrier concentration and morphological degradation was observed at high $\mathrm{Mg}$ concentrations $\left([\mathrm{Mg}] \sim 2 \times 10^{20} \mathrm{~cm}^{-3}\right)$ for $\mathrm{GaN}$ a and $\mathrm{Al}_{0.69} \mathrm{Ga}_{0.31} \mathrm{~N}\left([\mathrm{Mg}]>1 \times 10^{19} \mathrm{~cm}^{-3}\right)[106,108]$.

As-grown $\mathrm{Mg}$ doped $\mathrm{AlGaN}$ is highly resistive since $\mathrm{H}$ forms a neutral complex together with $\mathrm{Mg}$ causing passivation of the $\mathrm{Mg}$ acceptors [34,109,110]. $\mathrm{H}$ is always present in MOCVD growth as it is used as the $\mathrm{H}_{2}$ carrier gas and in the precursors (TMA, TMG, $\mathrm{NH}_{3}$ ). Annealing in $\mathrm{N}_{2}$ or $\mathrm{O}_{2}$ ambient was found to be an effective method to reduce the $\mathrm{H}$ by out-diffusion and to activate the $\mathrm{Mg}$ acceptors and achieve p-type conductive GaN and AlN [97,111].

High Al-content p-type conductive $\mathrm{Al}_{\mathrm{x}} \mathrm{Ga}_{1-\mathrm{x}} \mathrm{N}$ and $\mathrm{AlN}$ using $\mathrm{Mg}$ have been reported $[10,108,69,112-114]$. At $\mathrm{Al}$ contents of $\mathrm{x} \sim 0.45$ a low resistivity of $8 \Omega \mathrm{cm}$ was obtained [69] at room temperature whereas at higher Al-content $\mathrm{x} \sim 0.7$ the resistivity increased to 100000 $\Omega \mathrm{cm}$ [112]. Recently a low resistivity of $47 \Omega \mathrm{cm}$ was reported for $\mathrm{Al}_{0.7} \mathrm{Ga}_{0.3} \mathrm{~N}$ [114] indicating that there is a very narrow growth window for $p$-type doping at this $\mathrm{Al}$ contents. The narrow growth window may be explained either by the formation energy of $V_{N}$ which is expected to be reduced in p-type materials [110], by unintentionally incorporated Si and O donors or by over doping [108].

In Table 4.2 our results from the p-type doping are shown in comparison to the reported values. We obtained a resistivity of $\sim 7 \mathrm{k} \Omega \mathrm{cm}$ after in-situ annealing in nitrogen at $900{ }^{\circ} \mathrm{C}$ and a pressure of 700 mbar. In Figure 4.3 the $\mathrm{H}$ concentration in the sample before and after annealing, as measured by SIMS is shown. After annealing the hydrogen decreased by a factor of 5 to $[\mathrm{H}] \sim 5 \times 10^{17} \mathrm{~cm}^{-3}$ which is sufficient to obtain measureable conductivity. The growth and measurement details are reported in paper 5 . 


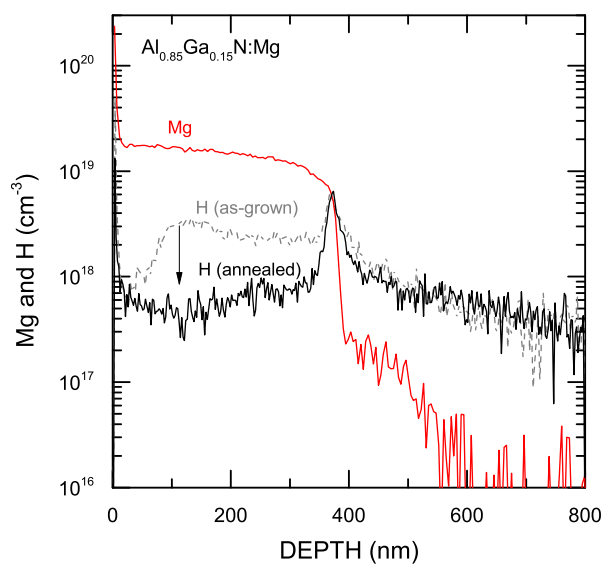

Figure 4.3 SIMS depth profile of $M g$ doped $A l_{0.85} G a_{0.15} \mathrm{~N}$ before and after annealing. The $\mathrm{Mg}$ concentration was unchanged after the annealing step while the $H$ concentration reduced by $a$ factor of $\sim 5$. The annealing was performed inside the MOCVD reactor at a temperature of $900{ }^{\circ} \mathrm{C}$ and in $\mathrm{N} 2$ ambient with a pressure of $700 \mathrm{mbar}$. 


\section{Characterization}

\subsection{X-ray diffraction}

$\mathrm{X}$-ray diffraction (XRD) is a powerful tool to access structural information such as thickness, alloy composition, residual strain, and defect structure, of epitaxial films and device structures [28]. In addition, XRD is a non-destructive characterization technique that does not require any special sample preparation, which makes it convenient to use for fast feedback characterization to control the growth process. These factors have made this technique very popular and widely used for structural characterization of epitaxial III-nitrides.

X-ray radiation (f.e. $\lambda_{\text {Cual } 1} \approx 1.5406 \AA$ in our setup) has a wavelength that is similar to the periodic lattice spacing in crystals of a few Ångstöm which make it possible to measure the crystallographic structure in crystals. Elastic scattering of the X-rays by the strongly bond core electrons gives rise to diffraction effects. Constructive interference for a set of lattice planes (hkl) occurs when Bragg's law is fulfilled:

$n \lambda=2 d_{h k l} \sin (\theta)$

where $n$ is a integer, $\lambda$ wavelength of the incident X-ray, $d_{h k l}$ is the interplanar spacing between two adjacent planes $(h k l)$ in the crystal lattice and $\theta$ is the angle between the incident X-ray and the measured plane. The $\mathrm{AlGaN}$ and AlN layers were studied by a high resolution (HR) triple-axis diffractometer using either a hybrid mirror or a 4-bounce monochromator as primary optics and a three-bounce analyzer crystal giving a resolution in the order of $\sim 0.003^{\circ}$. In HRXRD the sample can be rotated around the $2 \theta, \omega, \varphi$, and $\chi$ angles [Figure 5.1] to access certain planes.

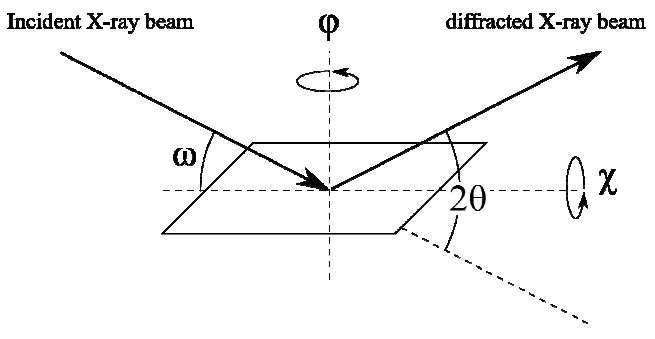

Figure 5.1 Schematic of the rotational geometry of the sample where $\omega$ is the angle formed between the sample surface and the incident $X$-ray and $2 \theta$ is the angle between the incident and scattered $X$-ray. For symmetric measurements $\theta=\omega$. 
In this work XRD was used to determine the residual strain (paper2 and $\mathbf{3}$ ), alloy composition (paper 2) and the lattice parameters and structural quality (paper 7).

\section{Lattice parameters and strain}

In wurtzite crystal structures the lattice spacing $d_{h k l}$ between two adjacent planes (hkl), is given by $[116,117]$ :

$$
d_{h k l}=\sqrt{\frac{1}{\left(h^{2}+k^{2}+h k\right) \frac{4}{3 a^{2}}+\frac{l^{2}}{c^{2}}}},
$$

The lattice parameters, $a$ and $c$, can be determined by measuring $2 \theta / \omega$ scans of at least one symmetric $(\theta=\omega)$ and one asymmetric $(\theta \neq \omega)$ reflection. From the symmetric lattice spacing $\mathrm{d}_{\mathrm{hkl}}$ determined from Eq. (5.1) the $c$ lattice parameter can be found using Eq. (5.2). Then by using the determined $c$ lattice parameter and the lattice spacing of the asymmetric reflection one can determine the $a$ lattice parameter. Since the error in the $c$ lattice parameter propagates to the determined $a$ lattice parameter, the precision of the determined $a$ lattice parameter is worse than for the $c$ lattice parameter.

For high quality crystals with sharp peaks the precision of the measurements is in the order of $\sim 0.0001 \AA$ for the lattice parameters. Using more sophisticated methods this precision can be further improved by about one order [116,117]. With such high precision, it is possible to study the effect of doping and stoichiometry on the lattice parameters. However, for heteroepitaxial layers the lattice parameters slightly vary over the layer thickness, which makes it not possible to obtain lattice parameters to that precision. After extraction of the lattice parameter values, the in-plain and out-of-plain strain can then be determined directly from these:

$\varepsilon_{x x} \equiv \frac{a-a_{0}}{a_{0}}, \varepsilon_{z z} \equiv \frac{c-c_{0}}{c_{0}}$,

where $\mathrm{a}_{0}$ and $\mathrm{c}_{0}$ is the relaxed lattice parameters. The data for the lattice parameters varies in the literature which causes an error in the determined strain as discussed in paper 7.

The composition of $\mathrm{AlGaN}$ can also be estimated from the measured lattice parameters. Since large strains are present due to heteroepitaxial growth and thermal lattice mismatches it is necessary to take the strain into account when the composition is determined. As a first approximation it is assuming that the layers are biaxial strained (see chapter 2),

$$
\frac{c-c_{0}(x)}{c_{0}(x)}=R_{B}(x) \frac{a-a_{0}(x)}{a_{0}(x)}
$$

where $\mathrm{a}_{0}(\mathrm{x}), \mathrm{c}_{0}(\mathrm{x})$, and $\mathrm{R}_{\mathrm{B}}(\mathrm{x})$ are the relaxed lattice parameters and biaxial relaxation coefficient $\left(=-2 \mathrm{C}_{13}(\mathrm{x}) / \mathrm{C}_{33}(\mathrm{x})\right)$ for $\mathrm{Al}_{\mathrm{x}} \mathrm{Ga}_{1-\mathrm{x}} \mathrm{N}$. It is further assumed that the relaxed lattice parameters and the biaxial relaxation coefficient, $\mathrm{R}_{\mathrm{B}}$, linearly vary between GaN and $\mathrm{AlN}$ :

$$
a_{0}(x)=x a_{0}^{A I N}+(1-x) a_{0}^{G a N}
$$




$$
\begin{aligned}
& c_{0}(x)=x c_{0}^{A I N}+(1-x) c_{0}^{G a N} \\
& R_{B}(x)=x R_{B}^{A I N}+(1-x) R_{B}^{G a N}
\end{aligned}
$$

Since the Eq. (5.4) is cubic, solving it gives three different solutions, where one of them gives a value between $0 \leq x \leq 1$ which is the alloy composition, $x$. The relaxed lattice parameters for $\mathrm{Al}_{\mathrm{x}} \mathrm{Ga}_{1-\mathrm{x}} \mathrm{N}$, can then be calculated from in Eq. (5.5) and (5.6) to determine the relaxed lattice parameters of $\mathrm{Al}_{\mathrm{x}} \mathrm{Ga}_{1-\mathrm{x}} \mathrm{N}$ and thereby the strain Eq. (5.3).

\section{Structural properties}

To study the structural properties the broadening of the diffraction peaks can be analyzed $[118,119]$. The mosaic block model is used where the thin film is assume to be made of crystal blocks that are slightly misoriented relative to each other and are characterized by a vertical and horizontal coherence length and a tilt and twist angle [119].

The broadening of the $\omega$ rocking curve in mainly caused by a finite crystallite size as well as the tilt and twist of the crystallites and can be used as a figure of merit for the crystal quality [120]. Twist will cause distortion of the (h00) lattice planes that are perpendicular to the caxis. Due to the geometry of these planes, they are not easily accessible and the twist must be extracted by extrapolation using several asymmetric reflections at lower angle values down to $\chi=90^{\circ}$. For layers with randomly distributed dislocations the screw $\left(\mathrm{N}_{\mathrm{S}}\right)$ and $\left(\mathrm{N}_{\mathrm{E}}\right)$ edge dislocation density can then be estimated by [28]:

$$
\begin{aligned}
& N_{S}=\frac{\beta_{S}^{2}}{4.35 b_{S}^{2}} \\
& N_{E}=\frac{\beta_{E}^{2}}{4.35 b_{E}^{2}}
\end{aligned}
$$

where $\left|b_{S}\right|$ and $\left|b_{E}\right|$ are the length of the Burgers vectors for screw $\left(\left|b_{S}\right|=c\right)$ and edge $\left(\left|b_{\mathrm{E}}\right|=a\right)$ dislocations, respectively.

\subsection{Atomic force microscopy}

Scanning probe microscopy (SPM) is a surface sensitive technique that generates images with details in the nanometer scale by scanning the specimen with a probe and measuring the surface-probe interaction. Common types of SPM measure magnetic, electrical and mechanical probe-surface interactions.

In this work, atomic force microscopy (AFM) was used to study the surface topography of substrates and epitaxial films by measuring the force interaction between the tip and the surface. AFM works for both conductive and insulating samples, in contrast to many other technics, which is an advantage when insulating wide band-gap semiconductors, such as AlN, are studied.

AFM can operate in three different modes: (i) contact mode, where the tip is in physical contact with the surface and a strong force acts on the tip, (ii) non-contact mode, where the tip is not in contact with the surface but where the cantilever, vibrating above the surface, 
interacts with long range forces, and (iii) tapping mode where the tip is oscillating above the surface and only lightly touches the surface at the lowest point of its oscillation. All measurements in this work were performed in tapping mode.

In tapping mode, the oscillation amplitude of the cantilever is kept at a constant setpoint value (20-100 nm) by an electronic feedback loop that adjusts and records the vertical position of the cantilever as it is moved over the surface. The small amplitude changes are detected by a laser beam that is reflected on the cantilever. Then the height of the scanner is recorder as the tip scans the surface and forms the image.

The AFM measurements were performed using a Dimension 3100 scanning probe microscope from Vecco. The vertical resolution is general very high for AFM measurements and with the equipment used in this work the vertical resolution was limited to about 0.3 to $1 \AA$ due the background noise of the system. Thus, it is no problem to measure step height of one bilayer of AlN ( 2.5 $\AA$ ). The lateral resolution is in general worse and is strongly dependent by the shape of the tip. In this work tips with a nominal tip radius of curvature of 5-10 $\mathrm{nm}$ have been used, which limit the resolution to an order of $\sim 1-5 \mathrm{~nm}$.

\subsection{Scanning electron microscopy and cathodoluminescence}

Scanning electron miscopy (SEM) is a common technique for studies of the surface topography of a variety of conductive metals or semiconductors. Electrons are accelerated to energies between $\sim 1-30 \mathrm{keV}$ and bombard the sample surface under high vacuum conditions. The electron beam is scanned over the sample surface and the electron interaction with the specimen at different points of the surface is detected. As the beam of primary electrons hits the surface, the incident electrons lose their energy by different process that generate a number of different signals, such as secondary electrons, X-rays and cathodoluminescence (CL), which can be studied by different detectors that are attached to the SEM chamber. The secondary electrons have a rather low energy $(<50 \mathrm{eV})$ and thus it is only the secondary electrons generated very close to the surface that can escape and be detected. Since the secondary electrons are generated at the subsurface region they can be used to create an image of the surface topography. The CL signal on the other hand is generated as the primary electrons penetrate the material and generate electron-hole pairs that can recombine and generate photons which are detected.

CL imaging and spectroscopy can provide valuable information about the luminescence properties from semiconductor samples. Since the secondary electrons are recorded simultaneous, complementary information about the surface morphology can be obtained. The CL images can be recorded either at a certain emission wavelength selected by a grating, which is referred to as monochromatic imaging or by letting all light from the sample pass straight through to the detector and form a panchromatic image of the sample. An excellent example of the strength of CL imaging in combination with topographic imaging was demonstrated by Elsner et al. [121], where a strong correlation between quenched luminescence and surface terminated threading dislocations was shown.

By varying the acceleration voltage, the spatial resolution of the CL image changes drastically as calculated using Monte Carlo simulation software [122] as can be seen in Figure 5.2. A large acceleration voltage will spread the electrons over a large volume in the material, while low accelerating voltages give good spatial resolution. The change in acceleration voltage also 
makes it possible to study depth resolved CL by changing the acceleration voltage. If a small acceleration voltage of $5 \mathrm{kV}$ is applied the CL measurements become very surface sensitive and with a good spatial resolution compare to an acceleration voltage of $10 \mathrm{kV}$. In this work CL-SEM was used to study the luminescence properties by panchromatic imaging or by CL spectroscopy (paper 2, 6 and 7).

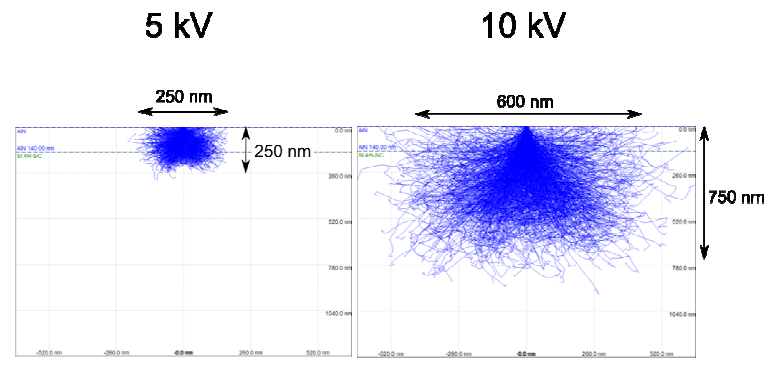

Figure 5.2 Monte Carlo simulation [122] of the electron propagation in AlN thin films using an electron acceleration voltage of 5 and $10 \mathrm{kV}$. The excitation volume becomes significantly larger at higher acceleration voltages, which results in a high CL intensity but a reduced lateral resolution in the CL image.

\subsection{Electrical characterization}

\section{Capacitance-Voltage profiling}

Capacitance-Voltage $(\mathrm{C}-\mathrm{V})$ profiling can be used to determine the net donor $\left(\mathrm{N}_{\mathrm{D}}-\mathrm{N}_{\mathrm{A}}\right)$ or net acceptor $\left(\mathrm{N}_{\mathrm{A}}-\mathrm{N}_{\mathrm{D}}\right)$ concentration as a function of the layer depth. A metal is put in contact with a semiconductor surface in order to form a Schottky barrier in the underlying epilayer where the free charge is depleted. The net donor concentration is determine by applying a reverse dc voltage and a small ac voltage test signal $(\sim 100 \mathrm{mV})$, which operates at frequency between $100 \mathrm{~Hz}$ up to $1 \mathrm{Mhz}$, in order to change the width of the depleted barrier. In order to use the technique for fast growth feedback, a liquid mercury probe was used to form the Schottky barrier while solid metallic contacts were used for temperature dependent measurements. The net donor concentration and the depth profile are given by [123]:

$N_{D}-N_{A}=\frac{-2}{q \varepsilon_{0} \varepsilon_{r} A^{2} d\left(C^{-2}\right) / d V}$

$x_{d}=\frac{\varepsilon_{0} \varepsilon_{r} A}{C}$

where $\varepsilon_{0} \varepsilon_{\mathrm{r}}$ is the dielectric permittivity of the layer, $\mathrm{A}$ is the area of the Schottky contact, $C$ is the capacitance, $q$ is the elementary charge and $\mathrm{x}_{\mathrm{d}}$ is the depth of the depletion region. To determine the $\mathrm{N}_{\mathrm{A}}-\mathrm{N}_{\mathrm{D}}$ concentration the sign in Eq. (5.10) is changed.

The local slope of the $\mathrm{C}^{-2}-\mathrm{V}$ curve gives the net doping concentration [Eq. (5.10)]. If the donors or acceptors are deep they may not be able to respond to the test signal at low 
temperatures. The emission time, $\tau$, for the electrons to be emitted to the conduction band is given by [124]:

$\tau_{e}=\frac{\exp \left(E_{C}-E_{T}\right)}{\sigma v_{t h} N_{C}}$

where $\mathrm{E}_{\mathrm{C}}-\mathrm{E}_{\mathrm{T}}$ is the energy between the conduction band and the trap level, $\sigma$ is the capture cross section and $v_{\text {th }}$ it the thermal velocity. By reducing the frequency of the test signal the electrons have more time to be emitted to the conduction band. It is also possible to enhance the electron emission by increasing the temperature.

\section{Transport measurements}

Measurements of the Hall effect can be used in order to determine the transport properties in semiconductors i.e. the carrier concentration (n or p), mobility $\left(\mu_{\mathrm{e}}\right.$ or $\left.\mu_{\mathrm{h}}\right)$ and type of carriers (n- or p-type). The carrier concentration is determined by measuring the Hall voltage formed when an external magnetic field $\mathbf{B}$ is applied perpendicular to the current flux. The carriers are deflected due to the Lorentz force induced by the magnetic field. The carrier concentration, resistivity, and mobility are determined by:

$$
\begin{aligned}
& n \approx \frac{-I B}{q V_{H} t}, p \approx \frac{I B}{q V_{H} t} \\
& \rho=\frac{1}{q\left(n \mu_{e}+p \mu_{h}\right)} \\
& \mu_{e} \approx \frac{1}{q n \rho}, \mu_{h} \approx \frac{1}{q p \rho}
\end{aligned}
$$

Typically, metal contacts are deposited onto diced test pieces from the wafer to measure the Hall effect in semiconductors, a process that destroys the sample for other measurements and is time consuming. It also becomes increasingly more difficult to obtain ohmic contacts on $\mathrm{AlGaN}$ layers with increasing $\mathrm{Al}$ contents [125]. Contactless measurements not only solve many of the described problems but also allow fast process feedback. In this work a microwave based Hall-probe technique was used to determine the carrier concentration, resistivity and mobility of the carriers. A circular waveguide directs microwaves $(10 \mathrm{GHz})$ perpendicular to the sample surface. The system measures interaction between the microwave and sample by recording the reflected power and polarization of the microwave at different magnetic field strength to determine the transport properties of the sample [126,127]. This technique requires that the layers are grown on semi-insulating substrates to determine electrical properties of the film and avoid disturbances from carriers present in the wafer. Reproducible results were obtained that were in good agreement with the other techniques used in this work such as $\mathrm{C}-\mathrm{V}$ and eddy current resistivity measurements. 


\subsection{Electron paramagnetic resonance}

Electron paramagnetic resonance (EPR) is known to be a powerful technique for defect characterization in semiconductors. EPR provides information on the spin multiplicity, symmetry and hyperfine interaction, allowing a conclusive identification of defects. For impurities with nuclear spin $I \neq 0$, chemical identification is possible based on the observed self-hyperfine structure. In many cases, energy levels of the studied defect can be revealed by using photoexcitation, often called photo-induced EPR or photo-EPR [128], or by monitoring the temperature dependence of the EPR signal $[129,130]$

EPR can be applied for defects that have an unpaired electron spin $S \neq 0$. Under an external magnetic field, the interaction between the electron spin $\mathrm{S}$ and external magnetic field splits the energy levels by the electronic Zeeman interaction into $2 \mathrm{~S}+1$ levels. These levels can be further split by hyperfine interaction between the electron spin $\mathrm{S}$ and a nuclear spin I (if the nuclear spins of the impurity and/or neighbouring atoms are different from zero). In the case of a single shallow donor impurity, one unpaired electron gives rise to $S=1 / 2$ and two electronic Zeeman levels corresponding to the magnetic quantum numbers $M_{S}= \pm 1 / 2$ will be observed. The splitting between these two levels is proportional to the external magnetic field strength and the Landé factor $\mathrm{g}$, which can be isotropic or a tensor depending on the symmetry of the defect. Transitions between the levels can be conveniently induced by microwave radiation. The resonance condition occurs when the photon energy of microwave hv equal to the splitting between the levels.

$\mathrm{h} v=\mu_{\mathrm{B}} \mathrm{gB}$

here $\mu_{\mathrm{B}}$ is the Bohr magneton $\left(5.79 \times 10^{-5} \mathrm{eV} / \mathrm{T}\right)$ and $\mathrm{B}$ the magnetic field strength. In a hexagonal lattice such as AlN, g is usually a tensor. For a single shallow donor in GaN, AlN or their alloys AlGaN, the highest symmetry is axial $\left(\mathrm{C}_{3 \mathrm{v}}\right)$. The g-factor is characteristic for each impurity or defect and can be used for defect characterization. The intensity of the EPR signal is proportional to the number of spins on the neutral donor state and can be used to estimate the donor concentration.

Silicon is predicted to undergo a transition from a shallow donor in GaN to a DX center in high-Al-content AlGaN. Such transition occurs when the Coulombic interaction between the $\mathrm{Si}$ donor and its surrounding environment causes a large lattice relaxation that breaks a $\mathrm{Si}-\mathrm{N}$ bond, putting Si slightly off the substitutional site. In such a case, the neutral Si donor prefers capturing another electron to relax to a lower-lying negatively charged state or the $\mathrm{DX}^{-}$state, following the process: $2 \mathrm{~d}^{0} \rightarrow \mathrm{DX}^{-}+\mathrm{d}^{+}\left(\mathrm{d}^{+}\right.$is the ionized state) [103,131]. In this work, EPR was used to estimate the $\mathrm{Si}$ donor concentration and to study the electronic structure of the $\mathrm{Si}$ donor/DX center in AlGaN.

EPR measurements were performed using an X-band ( $v \sim 9.4 \mathrm{GHz})$ E500 Bruker EPR spectrometer that is equipped with a continuous Helium-flow cryostat, allowing a regulation of the sample temperature from 4 to $295 \mathrm{~K}$. In the photo-EPR experiments, a halogen or xenon lamp and appropriate optical filters are used as excitation source. 


\subsection{SIMS}

Residual impurities that are unintentionally incorporated in the layers during the growth can significantly affect the electronic properties. Therefore it is important to know the amount of trace impurities that incorporate under different growth conditions in order to control the incorporation. Secondary ion mass spectrometry (SIMS) depth profiling is a powerful technique that can be used to detect very small concentrations of residual impurities as well as intentional doping profiles. SIMS uses ions to sputter the material and the resulting charged secondary ions from the material are detected and analyzed by a mass spectrometer.

SIMS measurements were performed by Evans Analytical Group in order to measure the doping and residual impurity concentrations as well as the alloy composition. The detection limit for oxygen and carbon was typically in the order of $\sim 2 \times 10^{17} \mathrm{~cm}^{-3}$. 


\section{References}

[1] Schwarz U 2008 Ultraviolet laser diodes: Indium-free success Nat. Photonics 2 521-2

[2] Khan A, Balakrishnan K and Katona T 2008 Ultraviolet light-emitting diodes based on group three nitrides Nat. Photonics 2 77-84

[3] Millan J, Godignon P, Perpina X, Perez-Tomas A and Rebollo J 2014 A Survey of Wide Bandgap Power Semiconductor Devices IEEE Trans. Power Electron. 29 2155-63

[4] Khan A 2006 Device physics: A bug-beating diode Nature 441 299-299

[5] Watanabe K, Taniguchi T and Kanda H 2004 Direct-bandgap properties and evidence for ultraviolet lasing of hexagonal boron nitride single crystal Nat. Mater. 3 404-9

[6] Makino T, Yoshino K, Sakai N, Uchida K, Koizumi S, Kato H, Takeuchi D, Ogura M, Oyama K, Matsumoto T, Okushi H and Yamasaki S 2011 Enhancement in emission efficiency of diamond deep-ultraviolet light emitting diode Appl. Phys. Lett. 99061110

[7] Butté R, Carlin J-F, Feltin E, Gonschorek M, Nicolay S, Christmann G, Simeonov D, Castiglia A, Dorsaz J, Buehlmann H J, Christopoulos S, Högersthal G B H von, Grundy A J D, Mosca M, Pinquier C, Py M A, Demangeot F, Frandon J, Lagoudakis P G, Baumberg J J and Grandjean N 2007 Current status of AlInN layers lattice-matched to GaN for photonics and electronics J. Phys. Appl. Phys. 406328

[8] Imura M, Sugimura H, Okada N, Iwaya M, Kamiyama S, Amano H, Akasaki I and Bandoh A 2008 Impact of high-temperature growth by metal-organic vapor phase epitaxy on microstructure of AlN on 6H-SiC substrates J. Cryst. Growth 310 2308-13

[9] Keller S and DenBaars S P 2003 Metalorganic chemical vapor deposition of group III nitrides-a discussion of critical issues J. Cryst. Growth 248 479-86

[10] Taniyasu Y, Kasu M and Makimoto T 2006 An aluminium nitride light-emitting diode with a wavelength of 210 nanometres Nature 441 325-8

[11] Kneissl M, Kolbe T, Chua C, Kueller V, Lobo N, Stellmach J, Knauer A, Rodriguez H, Einfeldt S, Yang Z, Johnson N M and Weyers M 2011 Advances in group III-nitridebased deep UV light-emitting diode technology Semicond. Sci. Technol. 26014036

[12] Taniyasu Y and Kasu M 2011 Origin of exciton emissions from an AlN p-n junction light-emitting diode Appl. Phys. Lett. 98131910

[13] Grandusky J R, Chen J, Gibb S R, Mendrick M C, Moe C G, Rodak L, Garrett G A, Wraback M and Schowalter L J 2013 270\,nm Pseudomorphic Ultraviolet LightEmitting Diodes with Over 60\,mW Continuous Wave Output Power Appl. Phys. Express 6032101

[14] Kinoshita T, Obata T, Nagashima T, Yanagi H, Moody B, Mita S, Inoue S, Kumagai Y, Koukitu A and Sitar Z 2013 Performance and Reliability of Deep-Ultraviolet LightEmitting Diodes Fabricated on AlN Substrates Prepared by Hydride Vapor Phase Epitaxy Appl. Phys. Express 6092103

[15] Shatalov M, Sun W, Lunev A, Hu X, Dobrinsky A, Bilenko Y, Yang J, Shur M, Gaska R, Moe C, Garrett G and Wraback M 2012 AlGaN Deep-Ultraviolet Light-Emitting Diodes with External Quantum Efficiency above 10\% Appl. Phys. Express 5082101 
[16] Cich M J, Aldaz R I, Chakraborty A, David A, Grundmann M J, Tyagi A, Zhang M, Steranka F M and Krames M R 2012 Bulk GaN based violet light-emitting diodes with high efficiency at very high current density Appl. Phys. Lett. 101223509

[17] Hirayama H, Fujikawa S, Noguchi N, Norimatsu J, Takano T, Tsubaki K and Kamata N 2009 222-282 nm AlGaN and InAlGaN-based deep-UV LEDs fabricated on highquality AlN on sapphire Phys. Status Solidi A 206 1176-82

[18] Ambacher O 1998 Growth and applications of Group III-nitrides J. Phys. Appl. Phys. 312653

[19] Novikov S V, Zainal N, Akimov A V, Staddon C R, Kent A J and Foxon C T 2010 Molecular beam epitaxy as a method for the growth of freestanding zinc-blende (cubic) GaN layers and substrates J. Vac. Sci. Technol. B 28 C3B1-C3B6

[20] Bernardini F, Fiorentini V and Vanderbilt D 1997 Spontaneous polarization and piezoelectric constants of III-V nitrides Phys. Rev. B 56 R10024-R10027

[21] Waltereit P, Brandt O, Trampert A, Grahn H T, Menniger J, Ramsteiner M, Reiche M and Ploog K H 2000 Nitride semiconductors free of electrostatic fields for efficient white light-emitting diodes Nature 406 865-8

[22] Simon J, Protasenko V, Lian C, Xing H and Jena D 2010 Polarization-Induced Hole Doping in Wide-Band-Gap Uniaxial Semiconductor Heterostructures Science 327 60-4

[23] Li S, Zhang T, Wu J, Yang Y, Wang Z, Wu Z, Chen Z and Jiang Y 2013 Polarization induced hole doping in graded AlxGa1-xN (x = $0.7 \sim 1)$ layer grown by molecular beam epitaxy Appl. Phys. Lett. 102062108

[24] Sun H and Moustakas T D 2014 UV emitters based on an AlGaN p-n junction in the form of graded-index separate confinement heterostructure Appl. Phys. Express 7 012104

[25] Noyan I C and Cohen J B 1987 Residual stress: measurement by diffraction and interpretation (Springer)

[26] Romanov A E, Baker T J, Nakamura S, Speck J S and Group E U 2006 Strain-induced polarization in wurtzite III-nitride semipolar layers J. Appl. Phys. 100023522

[27] Paszkowicz W, Podsiadło S and Minikayev R 2004 Rietveld-refinement study of aluminium and gallium nitrides J. Alloys Compd. 382 100-6

[28] Moram M A and Vickers M E 2009 X-ray diffraction of III-nitrides Rep. Prog. Phys. 72 036502

[29] Wright A F 1997 Elastic properties of zinc-blende and wurtzite AlN, GaN, and InN J. Appl. Phys. 822833

[30] Morales F M, Mánuel J M, García R, Reuters B, Kalisch H and Vescan A 2013 Evaluation of interpolations of $\mathrm{InN}, \mathrm{AlN}$ and GaN lattice and elastic constants for their ternary and quaternary alloys J. Phys. Appl. Phys. 46245502

[31] Manasevit H M, Erdmann F M and Simpson W I 1971 The Use of Metalorganics in the Preparation of Semiconductor Materials IV . The Nitrides of Aluminum and Gallium $J$. Electrochem. Soc. 118 1864-8 
[32] Dupuis R D and Dapkus P D 2008 Continuous room-temperature operation of $\mathrm{Ga}(1-\mathrm{x}) \mathrm{AlxAs-GaAs}$ double-heterostructure lasers grown by metalorganic chemical vapor deposition Appl. Phys. Lett. 32 406-7

[33] Amano H, Kito M, Hiramatsu K and Akasaki I 1989 P-Type Conduction in Mg-Doped GaN Treated with Low-Energy Electron Beam Irradiation (LEEBI) Jpn. J. Appl. Phys. 28 L2112

[34] Nakamura S, Mukai T, Senoh M and Iwasa N 1992 Thermal Annealing Effects on PType Mg-Doped GaN Films Jpn. J. Appl. Phys. 31 L139

[35] Nakamura S, Senoh M, Nagahama S, Iwasa N, Yamada T, Matsushita T, Kiyoku H and Sugimoto Y 1996 InGaN-Based Multi-Quantum-Well-Structure Laser Diodes Jpn. J. Appl. Phys. 35 L74-L76

[36] Jones A C and Hitchman M L 2009 Chemical Vapour Deposition: Precursors, Processes and Applications (Royal Society of Chemistry)

[37] Stringfellow G B 1999 Organometallic Vapor-Phase Epitaxy: Theory and Practice (Academic Press)

[38] Schubert E F 1993 Doping in III-V Semiconductors (Cambridge England ; New York, NY, USA: Cambridge University Press)

[39] Kakanakova-Georgieva A, Ciechonski R R, Forsberg U, Lundskog A and Janzén E 2009 Hot-Wall MOCVD for Highly Efficient and Uniform Growth of AlN Cryst. Growth Des. 9 880-4

[40] Kordina O, Hallin C, Henry A, Bergman J P, Ivanov I, Ellison A, Son N T and Janzén E 1997 Growth of SiC by "Hot-Wall" CVD and HTCVD Phys. Status Solidi B 202 321-34

[41] Danielsson Ö, Hallin C and Janzén E 2003 Reducing stress in silicon carbide epitaxial layers J. Cryst. Growth 252 289-96

[42] Koleske D D, Wickenden A E, Henry R L, DeSisto W J and Gorman R J 1998 Growth model for GaN with comparison to structural, optical, and electrical properties J. Appl. Phys. 841998

[43] Taniyasu Y, Kasu M and Makimoto T 2007 Threading dislocations in heteroepitaxial AlN layer grown by MOVPE on SiC ( $\left(\begin{array}{llll}0 & 0 & 0 & 1\end{array}\right)$ substrate J. Cryst. Growth 298 310-5

[44] Khan M A, Skogman R A, Hove J M V, Olson D T and Kuznia J N 1992 Atomic layer epitaxy of GaN over sapphire using switched metalorganic chemical vapor deposition Appl. Phys. Lett. 60 1366-8

[45] Zhang J P, Wang H M, Sun W H, Adivarahan V, Wu S, Chitnis A, Chen C Q, Shatalov M, Kuokstis E, Yang J W and Khan M A 2003 High-quality AlGaN layers over pulsed atomic-layer epitaxially grown AIN templates for deep ultraviolet light-emitting diodes J. Electron. Mater. 32 364-70

[46] Chen Z, Newman S, Brown D, Chung R, Keller S, Mishra U K, Denbaars S P and Nakamura S 2008 High quality AlN grown on SiC by metal organic chemical vapor deposition Appl. Phys. Lett. 93191906 
[47] Banal R G, Funato M and Kawakami Y 2009 Growth characteristics of AlN on sapphire substrates by modified migration-enhanced epitaxy J. Cryst. Growth 311 2834-6

[48] Davis R F 20113.09 - Organometallic Vapor Phase Epitaxial Growth of Group III Nitrides Comprehensive Semiconductor Science and Technology ed P Bhattacharya, R Fornari and H Kamimura (Amsterdam: Elsevier) pp 339-67

[49] Watson I M 2013 Metal organic vapour phase epitaxy of AlN, GaN, InN and their alloys: A key chemical technology for advanced device applications Coord. Chem. Rev. $2572120-41$

[50] Gibart P 2004 Metal organic vapour phase epitaxy of GaN and lateral overgrowth Rep. Prog. Phys. 67667

[51] Mihopoulos T G, Gupta V and Jensen K F 1998 A reaction-transport model for AlGaN MOVPE growth J. Cryst. Growth 195 733-9

[52] Lobanova A V, Mazaev K M, Talalaev R A, Leys M, Boeykens S, Cheng K and Degroote S 2006 Effect of V/III ratio in AIN and AlGaN MOVPE J. Cryst. Growth 287 $601-4$

[53] Lobanova A V, Segal A S, Yakovlev E V and Talalaev R A 2012 AlInN MOVPE: Growth chemistry and analysis of trends J. Cryst. Growth 352 199-202

[54] Kakanakova-Georgieva A, Gueorguiev G K, Stafström S, Hultman L and Janzén E 2006 AlGaInN metal-organic-chemical-vapor-deposition gas-phase chemistry in hydrogen and nitrogen diluents: First-principles calculations Chem. Phys. Lett. $431346-$ 51

[55] Reitmeier Z J, Einfeldt S, Davis R F, Zhang X, Fang X and Mahajan S 2009 Sequential growths of $\mathrm{AlN}$ and $\mathrm{GaN}$ layers on as-polished $6 \mathrm{H}-\mathrm{SiC}(0001)$ substrates Acta Mater. 57 4001-8

[56] Reitmeier Z J, Einfeldt S, Davis R F, Zhang X, Fang X and Mahajan S 2010 Surface and defect microstructure of GaN and AlN layers grown on hydrogen-etched $6 \mathrm{H}-$ $\mathrm{SiC}(0001)$ substrates Acta Mater. 58 2165-75

[57] Okumura H, Kimoto T and Suda J 2012 Over-700-nm Critical Thickness of AlN Grown on 6H-SiC(0001) by Molecular Beam Epitaxy Appl. Phys. Express 5105502

[58] Floro J A, Follstaedt D M, Provencio P, Hearne S J and Lee S R 2004 Misfit dislocation formation in the AlGaN/GaN heterointerface J. Appl. Phys. 96 7087-94

[59] Barghout $\mathrm{K}$ and Chaudhuri J 2004 Calculation of residual thermal stress in GaN epitaxial layers grown on technologically important substrates J. Mater. Sci. 39 5817-23

[60] Liu L, Liu B, Edgar J H, Rajasingam S and Kuball M 2002 Raman characterization and stress analysis of AlN grown on SiC by sublimation J. Appl. Phys. 92 5183-8

[61] Ohring M 2001 Materials Science of Thin Films, Second Edition (San Diego, CA: Academic Press)

[62] Cimalla V, Pezoldt J and Ambacher O 2007 Group III nitride and SiC based MEMS and NEMS: materials properties, technology and applications J. Phys. Appl. Phys. 40 6386 
[63] Liu L and Edgar J H 2002 Substrates for gallium nitride epitaxy Mater. Sci. Eng. R Rep. 37 61-127

[64] Taniyasu Y, Kasu M and Kobayashi N 2002 Intentional control of n-type conduction for Si-doped AlN and AlXGa1-XN $(0.42 \leqslant x<1)$ Appl. Phys. Lett. 81 1255-7

[65] Keller S, Cantu P, Moe C, Wu Y, Keller S, Mishra U K, Speck J S and DenBaars S P 2005 Metalorganic Chemical Vapor Deposition Conditions for Efficient Silicon Doping in High Al-Composition AlGaN Films Jpn. J. Appl. Phys. 447227

[66] Kuech T F, Veuhoff E and Meyerson B S 1984 Silicon doping of GaAs and AlxGa1-xAs using disilane in metalorganic chemical vapor deposition J. Cryst. Growth $6848-53$

[67] Fritze S, Dadgar A, Witte H, Bügler M, Rohrbeck A, Bläsing J, Hoffmann A and Krost A 2012 High Si and Ge n-type doping of GaN doping - Limits and impact on stress Appl. Phys. Lett. 100122104

[68] Zhang X, Kung P, Saxler A, Walker D, Wang T C and Razeghi M 1995 Growth of AlxGa1-xN:Ge on sapphire and silicon substrates Appl. Phys. Lett. 67 1745-7

[69] Jeon S-R, Ren Z, Cui G, Su J, Gherasimova M, Han J, Cho H-K and Zhou L 2005 Investigation of $\mathrm{Mg}$ doping in high-Al content p-type AlxGa1-xN $(0.3<\mathrm{x}<0.5)$ Appl. Phys. Lett. 86082107

[70] Ohba Y and Hatano A 1994 A study on strong memory effects for Mg doping in $\mathrm{GaN}$ metalorganic chemical vapor deposition J. Cryst. Growth 145 214-8

[71] Walukiewicz W 2001 Intrinsic limitations to the doping of wide-gap semiconductors Phys. B Condens. Matter 302-303 123-34

[72] Huang D, Yun F, Reshchikov M A, Wang D, Morkoç H, Rode D L, Farina L A, Kurdak Ç, Tsen K T, Park S S and Lee K Y 2001 Hall mobility and carrier concentration in free-standing high quality GaN templates grown by hydride vapor phase epitaxy Solid-State Electron. 45 711-5

[73] Heikman S, Keller S, DenBaars S P and Mishra U K 2002 Growth of Fe doped semiinsulating GaN by metalorganic chemical vapor deposition Appl. Phys. Lett. 81 439-41

[74] Poblenz C, Waltereit P, Rajan S, Heikman S, Mishra U K and Speck J S 2004 Effect of carbon doping on buffer leakage in $\mathrm{AlGaN} / \mathrm{GaN}$ high electron mobility transistors $J$. Vac. Sci. Technol. B 22 1145-9

[75] Maruska H P and Tietjen J J 2003 THE PREPARATION AND PROPERTIES OF VAPOR-DEPOSITED SINGLE-CRYSTAL-LINE GaN Appl. Phys. Lett. 15 327-9

[76] Van de Walle C G, Stampfl C and Neugebauer J 1998 Theory of doping and defects in III-V nitrides J. Cryst. Growth 189-190 505-10

[77] Parish G, Keller S, Denbaars S P and Mishra U K 2000 SIMS investigations into the effect of growth conditions on residual impurity and silicon incorporation in $\mathrm{GaN}$ and AlxGa1-xN J. Electron. Mater. 29 15-20

[78] Zeisel R, Bayerl M W, Goennenwein S T B, Dimitrov R, Ambacher O, Brandt M S and Stutzmann M 2000 DX-behavior of Si in AlN Phys. Rev. B 61 R16283-R16286 
[79] Wetzel C, Suski T, Ager III J W, Weber E R, Haller E E, Fischer S, Meyer B K, Molnar R J and Perlin P 1997 Pressure Induced Deep Gap State of Oxygen in GaN Phys. Rev. Lett. 78 3923-6

[80] McCluskey M D, Johnson N M, Van de Walle C G, Bour D P, Kneissl M and Walukiewicz W 1998 Metastability of Oxygen Donors in AlGaN Phys. Rev. Lett. 80 4008-11

[81] Mattila T and Nieminen R M 1996 Ab initio study of oxygen point defects in GaAs, GaN, and AlN Phys. Rev. B 54 16676-82

[82] Silvestri L, Dunn K, Prawer S and Ladouceur F 2012 Concentration of point defects in wurtzite AlN: A hybrid functional study EPL Europhys. Lett. 9836003

[83] Pophristic M, Guo S P and Peres B 2003 High-conductivity n-AlGaN with high Al mole fraction grown by metalorganic vapor phase deposition Appl. Phys. Lett. 82 428991

[84] Nakarmi M L, Nepal N, Lin J Y and Jiang H X 2005 Unintentionally doped n-type Al0.67Ga0.33N epilayers Appl. Phys. Lett. 86261902

[85] MOTT N F 1968 Metal-Insulator Transition Rev. Mod. Phys. 40 677-83

[86] Götz W, Johnson N M, Chen C, Liu H, Kuo C and Imler W 1996 Activation energies of Si donors in GaN Appl. Phys. Lett. 68 3144-6

[87] Forghani K, Schade L, Schwarz U T, Lipski F, Klein O, Kaiser U and Scholz F 2012 Strain and defects in Si-doped (Al)GaN epitaxial layers J. Appl. Phys. 112093102

[88] Levinshtein M E, Rumyantsev S L and Shur M S 2001 Properties of Advanced Semiconductor Materials: GaN, AIN, InN, BN, SiC, SiGe (Wiley-Interscience)

[89] Vurgaftman I and Meyer J R 2003 Band parameters for nitrogen-containing semiconductors J. Appl. Phys. 94 3675-96

[90] Paskov P P, Monemar B, Toropov A, Bergman J P and Usui A 2007 Two-electron transition spectroscopy of shallow donors in bulk GaN Phys. Status Solidi C 4 2601-4

[91] Neuschl B, Thonke K, Feneberg M, Goldhahn R, Wunderer T, Yang Z, Johnson N M, Xie J, Mita S, Rice A, Collazo R and Sitar Z 2013 Direct determination of the silicon donor ionization energy in homoepitaxial AIN from photoluminescence two-electron transitions Appl. Phys. Lett. 103122105

[92] Yi G-C and Wessels B W 1996 Compensation of n-type GaN Appl. Phys. Lett. 69 3028-30

[93] Di Forte-Poisson M A, Huet F, Romann A, Tordjman M, Lancefield D, Pereira E, Di Persio J and Pecz B 1998 Relationship between physical properties and gas purification in GaN grown by metalorganic vapor phase epitaxy J. Cryst. Growth 195 314-8

[94] Nakarmi M L, Kim K H, Zhu K, Lin J Y and Jiang H X 2004 Transport properties of highly conductive n-type Al-rich AlxGa1-xN ( $\mathrm{x} \geqslant 0.7)$ Appl. Phys. Lett. 853769

[95] Borisov B, Kuryatkov V, Kudryavtsev Y, Asomoza R, Nikishin S, Song D Y, Holtz M and Temkin $\mathrm{H} 2005 \mathrm{Si}$-doped $\mathrm{AlxGa1}-\mathrm{xN}(0.56 \leqslant x \leqslant 1)$ layers grown by molecular beam epitaxy with ammonia Appl. Phys. Lett. 87132106 
[96] Mehnke F, Wernicke T, Pingel H, Kuhn C, Reich C, Kueller V, Knauer A, Lapeyrade M, Weyers M and Kneissl M 2013 Highly conductive n-Al x Ga1- x N layers with aluminum mole fractions above 80\% Appl. Phys. Lett. 103212109

[97] Taniyasu Y, Kasu M and Makimoto T 2006 Increased electron mobility in n-type Sidoped AlN by reducing dislocation density Appl. Phys. Lett. 89182112

[98] Mooney P M 1990 Deep donor levels (DX centers) in III-V semiconductors J. Appl. Phys. 67 R1-R26

[99] Skierbiszewski C, Suski T, Leszczynski M, Shin M, Skowronski M, Bremser M D and Davis R F 1999 Evidence for localized Si-donor state and its metastable properties in AlGaN Appl. Phys. Lett. 74 3833-5

[100] Chadi D J and Chang K J 1988 Theory of the Atomic and Electronic Structure of DX Centers in GaAs and AlxGa1-xAs Alloys Phys. Rev. Lett. 61 873-6

[101] Lang D V, Logan R A and Jaros M 1979 Trapping characteristics and a donor-complex (DX) model for the persistent-photoconductivity trapping center in Te-doped Al_\{x\}Ga_\{1-x \}As Phys. Rev. B 19 1015-30

[102] Silvestri L, Dunn K, Prawer S and Ladouceur F 2011 Hybrid functional study of Si and O donors in wurtzite AlN Appl. Phys. Lett. 99122109

[103] Park C H and Chadi D J 1997 Stability of deep donor and acceptor centers in GaN, AlN, and BN Phys. Rev. B 55 12995-3001

[104] Gordon L, Lyons J L, Janotti A and Van de Walle C G 2014 Hybrid functional calculations of DX centers in AlN and GaN Phys. Rev. B 89085204

[105] Szabó Á, Son N T, Janzén E and Gali A 2010 Group-II acceptors in wurtzite AlN: A screened hybrid density functional study Appl. Phys. Lett. 96192110

[106] Kozodoy P, Xing H, DenBaars S P, Mishra U K, Saxler A, Perrin R, Elhamri S and Mitchel W C 2000 Heavy doping effects in Mg-doped GaN J. Appl. Phys. 87 1832-5

[107] Nakarmi M L, Nepal N, Ugolini C, Altahtamouni T M, Lin J Y and Jiang H X 2006 Correlation between optical and electrical properties of Mg-doped AlN epilayers Appl. Phys. Lett. 89152120

[108] Chakraborty A, Moe C G, Wu Y, Mates T, Keller S, Speck J S, DenBaars S P and Mishra U K 2007 Electrical and structural characterization of Mg-doped p-type Al0.69Ga0.31N films on SiC substrate J. Appl. Phys. 101053717

[109] Neugebauer J and Van de Walle C G 1995 Hydrogen in GaN: Novel Aspects of a Common Impurity Phys. Rev. Lett. 75 4452-5

[110] Van de Walle C G and Neugebauer J 2004 First-principles calculations for defects and impurities: Applications to III-nitrides J. Appl. Phys. 953851

[111] Hull B A, Mohney S E, Venugopalan H S and Ramer J C 2000 Influence of oxygen on the activation of p-type GaN Appl. Phys. Lett. 76 2271-3

[112] Nakarmi M L, Kim K H, Khizar M, Fan Z Y, Lin J Y and Jiang H X 2005 Electrical and optical properties of Mg-doped Al0.7Ga0.3N alloys Appl. Phys. Lett. 86092108 
[113] Kakanakova-Georgieva A, Nilsson D, Stattin M, Forsberg U, Haglund A, Larsson A and Janzén E $2010 \mathrm{Mg}$-doped Al0.85Ga0.15N layers grown by hot-wall MOCVD with low resistivity at room temperature Phys. Status Solidi RRL - Rapid Res. Lett. 4 311-3

[114] Kinoshita T, Obata T, Yanagi H and Inoue S 2013 High p-type conduction in high-Al content Mg-doped AlGaN Appl. Phys. Lett. 102012105

[115] Taniyasu Y and Kasu M 2008 Aluminum nitride deep-ultraviolet light-emitting p-n junction diodes Diam. Relat. Mater. 17 1273-7

[116] Fewster P F and Andrew N L 1995 Absolute Lattice-Parameter Measurement J. Appl. Crystallogr. 28 451-8

[117] Fatemi M 2005 Absolute measurement of lattice parameter in single crystals and epitaxic layers on a double-crystal X-ray diffractometer Acta Crystallogr. A 61 301-13

[118] Srikant V, Speck J S and Clarke D R 1997 Mosaic structure in epitaxial thin films having large lattice mismatch J. Appl. Phys. 82 4286-95

[119] Chierchia R, Böttcher T, Heinke H, Einfeldt S, Figge S and Hommel D 2003 Microstructure of heteroepitaxial GaN revealed by x-ray diffraction J. Appl. Phys. 93 $8918-25$

[120] Heying B, Wu X H, Keller S, Li Y, Kapolnek D, Keller B P, DenBaars S P and Speck J S 1996 Role of threading dislocation structure on the $\mathrm{x}$-ray diffraction peak widths in epitaxial GaN films Appl. Phys. Lett. 68 643-5

[121] Elsner J, Jones R, Haugk M, Gutierrez R, Frauenheim T, Heggie M I, Öberg S and Briddon P R 1998 Effect of oxygen on the growth of (1010) GaN surfaces: The formation of nanopipes Appl. Phys. Lett. 733530

[122] Drouin D, Couture A R, Joly D, Tastet X, Aimez V and Gauvin R 2007 CASINO V2.42-A Fast and Easy-to-use Modeling Tool for Scanning Electron Microscopy and Microanalysis Users Scanning 29 92-101

[123] Orton J W and Blood P 1990 The electrical characterization of semiconductors: measurement of minority carrier properties / J.W. Orton and P. Blood (London: Academic, cop. 1990)

[124] Schroder D K 2006 Semiconductor Material and Device Characterization (John Wiley \& Sons)

[125] France R, Xu T, Chen P, Chandrasekaran R and Moustakas T D 2007 Vanadium-based Ohmic contacts to n-AlGaN in the entire alloy composition Appl. Phys. Lett. 90062115

[126] Nguyen D, Hogan K, Blew A and Cordes M 2004 Improved process control, lowered costs and reduced risks through the use of non-destructive mobility and sheet carrier density measurements on GaAs and GaN wafers J. Cryst. Growth 272 59-64

[127] Beck W A and Anderson J R 1987 Determination of electrical transport properties using a novel magnetic field-dependent Hall technique J. Appl. Phys. 62 541-54

[128] Son N T, Trinh X T, Løvlie L S, Svensson B G, Kawahara K, Suda J, Kimoto T, Umeda T, Isoya J, Makino T, Ohshima T and Janzén E 2012 Negative-U System of Carbon Vacancy in 4H-SiC Phys. Rev. Lett. 109187603

[129] Son N T, Bickermann M and Janzén E 2011 Shallow donor and DX states of Si in AlN Appl. Phys. Lett. 98092104 
[130] Trinh X T, Nilsson D, Ivanov I G, Janzén E, Kakanakova-Georgieva A and Son N T 2013 Negative-U behavior of the Si donor in Al0.77Ga0.23N Appl. Phys. Lett. 103 042101

[131] Bogusławski P and Bernholc J 1997 Doping properties of C, Si, and Ge impurities in GaN and AlN Phys. Rev. B 56 9496-505 


\section{Part II - Papers}





\section{Part II}

\section{Papers}

The articles associated with this thesis have been removed for copyright reasons. For more details about these see:

http://urn.kb.se/resolve?urn=urn:nbn:se:liu:diva-106733 